Estudios Constitucionales, Año 10, No 1, 2012, pp. 15 - 64.

ISSN 0718-0195

Centro de Estudios Constitucionales de Chile Universidad de Talca

"Los efectos de las sentencias en el proceso de inaplicabilidad en Chile:

examen a un quinquenio de la Reforma Constitucional"

Manuel A. Núñez Poblete

\title{
LOS EFECTOS DE LAS SENTENCIAS EN EL PROCESO DE INAPLICABILIDAD EN CHILE: EXAMEN A UN QUINQUENIO DE LA REFORMA CONSTITUCIONAL $\left(^{*}\right)$ \\ The Effects of Inapplicability Judgment in Chile: An Analysis after Five Years of Constitutional Reform
}

\author{
Manuel A. NúNEzZ Poblete $\left(^{* *}\right)$ \\ Profesor Facultad de Derecho de la Pontificia Universidad Católica de Valparaíso \\ manuel.nunez@ucv.cl.
}

RESUMEN: La presente investigación explica los efectos que surten las sentencias dictadas en los procesos de inaplicabilidad tanto para el propio Tribunal Constitucional como frente al tribunal que conoce de la gestión. Dichos efectos son desglosados en sentencias formales que no son de mérito y en las decisiones de fondo desestimatorias y estimatorias. El Autor propone, a partir de la naturaleza hibrida de la inaplicabilidad, una interpretación armónica de la competencia declaratoria de inaplicabilidady de las facultades jurisdiccionales de los jueces del fondo. Desde el punto de vista metodológico, el trabajo contrasta las decisiones de inaplicabilidad con la suerte posterior de las gestiones judiciales.

ABSTRACT: This research aims to explain the legal effects of inapplicability judgment before the Constitutional Court and the lower courts. The multiple effects are developed separating the formal from the substantive decisions. The Author's proposal is the coordinated interpretation of the inapplicability competence and the judicial powers of lower courts. This essay offers a necessary comparison between inapplicability judgments and the final decisions of lower courts.

PALABRAS CLAVE: Inaplicabilidad / Sentencia de inaplicabilidad / cosa juzgada / preclusión / inadmisibilidad de la acción

KEY WORDS: Inapplicability judgment / claim preclusion / preclusion / application inadmissibility

\footnotetext{
*Artículo recibido el 13 de marzo de 2012 y aprobado el 2 de mayo de 2012.

" Facultad de Derecho de la Pontificia Universidad Católica de Valparaíso, Departamento de Derecho público. El presente trabajo forma parte del Proyecto de investigación núm. 1090607, patrocinado por el Fondo Nacional de Desarrollo Científico y Tecnológico (Fondecyt) y del cual el autor es investigador principal. El autor agradece la valiosa información judicial que aportaron los abogados Francisco Pastén del Consejo de Defensa del Estado, Ignacio Barrientos y Pablo Ardouin, ambos de la Defensoría Penal Pública y los abogados particulares Rodrigo Astorga y Alfredo Maira. El autor agradece también los comentarios del Profesor Rodrigo Pica, coinvestigador en este proyecto de investigación. Correo electrónico del autor: manuel.nunez@ucv.cl.
} 


\section{INTRODUCCIÓN}

Como es bien sabido, la reforma de la Ley No 20.050 de 2005 radicó en el Tribunal Constitucional la tarea de resolver la inaplicabilidad de las leyes. Después de muchos años de decaimiento, el principal instituto judicial de control de la legislación fue trasladado desde la cúspide de la organización judicial tradicional chilena, la Corte Suprema, hasta la órbita de competencia de un renovado Tribunal Constitucional. Como la reforma introducida al instituto de la inaplicabilidad no fue sólo de lugar sino sobre todo de diseño sustantivo, ha sido preciso para la doctrina definir los contornos de una competencia que acaba de cumplir su primer quinquenio. La presente investigación se centra en los efectos de las decisiones de término propias de los procesos de inaplicabilidad, entendiendo aquí por sentencias de término no sólo aquellas que ponen fin al proceso de inaplicabilidad sino aquellas que impiden su incoación (propiamente, sentencias de inadmisión). Estos efectos serán examinados en el contexto que es propio de la gestión judicial en que inciden las decisiones del Tribunal Constitucional, sin entrar a analizar los efectos exteriores a dicho proceso y que se concretan en la competencia para declarar la inconstitucionalidad de un precepto ya declarado inaplicable o en la extrapolación de las decisiones de inaplicabilidad más allá de los límites que son propios de la gestión judicial. Por esta razón, y como lo sugiere el propio título, se examinarán los efectos que corresponde asignar a las sentencias constitucionales sólo en la medida en que influyen sobre el curso de la gestión judicial que sirve de plataforma insustituible para la promoción de la pretensión de inaplicabilidad.

Para identificar el alcance de los efectos de las sentencias, la investigación se apoya, por una parte, en la dogmática nacional y comparada, ajustando sus proposiciones a las peculiaridades de un instituto procesal que por su originalidad relativa no es enteramente equivalente a las atribuciones de control de la ley que poseen otros tribunales constitucionales. Por otra parte, la investigación no se agota en la decisión constitucional sino que pretende dar un paso adicional a través del examen del curso que ha seguido la gestión con posterioridad a la sentencia del Tribunal Constitucional. Es un examen de esta última naturaleza el que permite identificar las dificultades que emanan de una inadecuada comprensión del instituto en análisis. Como el seguimiento de los procesos no sólo es interminable sino también ocasionalmente muy difícil (por las dificultades informáticas o de reserva que son propias de algunos expedientes), se han seleccionado algunos casos que bien ilustrarán al lector sobre el difícil curso que sigue a la sentencia tras el proceso de inaplicabilidad.

En forma previa al análisis de sus efectos, el estudio contextualiza la sentencia en un proceso y precisa la noción de cosa juzgada que se manejará con el fin de 
explicar la fuerza vinculante de las decisiones propias de la cuestión de inaplicabilidad. En seguida, el estudio aborda los efectos de las decisiones de inadmisión a trámite y de inadmisibilidad propiamente tales, como modalidades de resolución diversas a los fallos de mérito. Estos últimos fallos, a su turno, se descomponen analíticamente en sentencias desestimatorias y sentencias estimatorias, las que en su faz problemática y crítica son analizadas en correspondencia con el curso que sigue la gestión judicial en que incide -o debe incidir el fallo de inaplicabilidad. Como se intenta demostrar en las páginas que siguen, el diseño particular de esta fórmula de control concreto obliga a modular el modo en que los tribunales de la nación, en general, comprenden la noción de jurisdicción contenida en el art. 76 CPR, y la Corte Suprema, en particular, entiende la superintendencia que le atribuye el art. $82 \mathrm{CPR}$. Ambos atributos, deben necesariamente coordinarse con esta nueva invitada al selecto club de instrumentos de control de la jurisdicción: la inaplicabilidad.

\section{ANTECEDENTES: CUESTIÓN DE INAPLICABILIDAD, PROCESO JURISDICCIONAL Y COSA JUZGADA}

La competencia a que se refiere el No 6 del art. 96 CPR, y que permite al Tribunal Constitucional resolver la inaplicabilidad de un precepto legal que puede surtir algún efecto contrario a la Constitución se ejerce en un doble contexto procesal. Por una parte, ella sólo puede ejercerse a instancia de las partes de la gestión o del tribunal que conoce de ella, y siempre que dicha gestión se encuentre pendiente. La primera hipótesis que condiciona el ejercicio de la jurisdicción del Tribunal consiste entonces en la existencia de un proceso pendiente que esté siendo conocido por cualquier tribunal de la nación. Sólo existiendo este primer proceso no afinado es posible la incoación de un segundo proceso mediante el ejercicio de una acción que la propia Constitución radica en las partes de la gestión o en el tribunal que conoce de ella. Aunque el interés de los actores es diverso, las partes obran en función de sus intereses subjetivos y los jueces en función del interés objetivo ${ }^{1}$, la pretensión es básicamente la misma: obtener del Tribunal Constitucional el pronunciamiento sobre la aplicabilidad o inaplicabilidad de un precepto legal en función de los efectos, compatibles o incompatibles con el texto constitucional, que éste produce en la gestión particular.

Durante algún tiempo se discutió la naturaleza del proceso de inaplicabilidad negándole su carácter recursivo y reconociéndole una naturaleza que oscilaba

\footnotetext{
${ }^{1}$ Sobre el interés de las partes y particularmente la legitimación activa del juez véanse la STC Rol № 1.029, 24 de noviembre de 2008 y el estudio de PICA (2010b), pp. 205-238.
} 
entre una acción o una excepción de inconstitucionalidad. Hoy, tras la reforma constitucional de la Ley No 20.050 y la modificación legal de la Ley No 20.381, no parece haber duda en que, de acuerdo con el lenguaje legal y la praxis constitucional, la cuestión de inaplicabilidad deba ser calificada como una acción. Sea que la intenten las partes o el juez de la gestión, la inaplicabilidad es un proceso que se inicia a través de una acción. Ella no es una consulta, que podrían erróneamente los jueces despachar como medida para mejor resolver ${ }^{2}$, ni una petición que el juez pueda formular como mensajero de la partes ${ }^{3}$. Por el contrario, ella supone el ejercicio de una acción que genera un proceso autónomo cuyo resultado somete a las partes y al tribunal a una decisión que es vinculante. Prima facie, esta obligatoriedad emana del carácter jurisdiccional de un órgano que, en el ejercicio de esta competencia y dados ciertos supuestos, no emite una opinión sino que despacha una orden. Si bien es muy discutible que esta competencia que el propio tribunal y la doctrina han considerado, no sin dificultades, como una forma de control concreto excluya absolutamente la competencia concurrente de los jueces para evitar que la aplicación de un precepto legal genere efectos contrarios a la Constitución ${ }^{4}$, lo cierto es que una vez activada por cualquiera de los sujetos dotados de legitimación activa el proceso que de ella resulta culmina en una decisión que vincula a la gestión, a sus partes y en los tribunales que conocen de ella.

Aunque no es un aspecto que pueda profundizarse en este lugar, es preciso recordar que tanto la acción que empuja el ejercicio de la jurisdicción, como el proceso que dirige esta última, giran en torno a la aplicación judicial de un precepto legal. En esa medida, como he advertido en otro lugar ${ }^{5}$, el proceso tanto tiene por objeto controlar la actividad del legislador como la de supervigilar a los órganos aplicadores del Derecho. Dicho de otro modo, el control de la legislación se mide sólo en función de los efectos que genera su aplicación a una gestión concreta, de donde resulta que la finalidad de esta acción constitucional de inaplicabilidad rozará muchas veces lo que es propio de los medios de revisión de las sentencias, esto es, de los recursos procesales. De aquí resulta, como se advierte más adelante, una naturaleza híbrida que no se sabe a ciencia cierta si fue querida por el

\footnotetext{
${ }^{2}$ La consideración de la inaplicabilidad como medida para mejor resolver se presentó desde los inicios del nuevo instituto, a partir de una errada concepción de lo que esta competencia constitucional entraña. Véase por ejemplo el oficio que abre el proceso que termina con la STC Rol No 541, 21 de diciembre de 2006.

${ }^{3}$ Véase, entre otras, la STC Rol No 1681, 11 de mayo de 2010.

${ }^{4}$ Este tema lo he tratado en mi estudio "La desaplicación y la inaplicación jurisdiccional de las leyes en Chile. Un estudio sobre su diferenciación conceptual y su incidencia en el ejercicio de la jurisdicción y del control concreto de constitucionalidad de las leyes" (en prensa).

${ }^{5}$ NúNEz (2008), pp. 153 y ss.
} 
constituyente, pero que no impide calificar la decisión del Tribunal como un acto jurisdiccional y, por lo tanto, como un mandato dotado de fuerza imperativa que puede asimilarse al de la fuerza de la cosa juzgada.

En general, la doctrina procesal constitucional discute la eficacia y la corrección de la extrapolación del instituto de la cosa juzgada hacia los procesos constitucionales, directos o incidentales contra la ley. La discusión dogmática ${ }^{6}$ hunde sus raíces en la compleja naturaleza, pseudo jurisdiccional para unos, jurisdiccional para otros de la revisión judicial de las leyes, particularmente cuando la sentencia del órgano constitucional afecta la validez y, por lo tanto, la vigencia de la ley. En la medida en que el tan peculiar proceso chileno de inaplicabilidad no altera la vigencia de la ley sino sólo su aplicación en el caso concreto, es que en este ensayo los efectos de la decisión de inaplicabilidad se examinarán a la luz del instituto procesal de la cosa juzgada y, por lo tanto, asumiendo como cierta la naturaleza jurisdiccional de la competencia declaratoria de la inaplicabilidad. Dentro de sus particularidades, que la distinguen de buena parte de los controles incidentales con efectos erga omnes, se tratará de una cosa juzgada restringida a los sujetos que participan del proceso, con la sola excepción del efecto extraprocesal que produce el fallo estimatorio y que es condición para el ejercicio la competencia del art. 93.7 CPR.

Para los efectos de la presente investigación, por cosa juzgada en sede de inaplicabilidad se entiende entonces el complejo haz de efectos propios del proceso constitucional, en virtud de los cuales (i) la decisión del Tribunal es obligatoria para las partes y los jueces de la gestión y, además, (ii) la discusión sobre un asunto ya decidido por el Tribunal no puede ser renovada en la misma gestión judicial ${ }^{7}$. Como puede advertirse, este concepto no es muy distinto de la noción general que maneja la dogmática procesal, lo que no obsta a que sus elementos constitutivos deban eventualmente ajustarse a las particularidades del proceso de inaplicabilidad.

La fuerza de cosa juzgada se proyecta hacia y desde las decisiones dictadas en los procesos de inaplicabilidad. En el primer caso, el proceso de inaplicabilidad es vinculado tanto por las sentencias dictadas por el mismo Tribunal en los procesos de control preventivo de las leyes (art. 93.1 y 3, en relación con el los arts. 51 inc. $2^{\circ}, 71$ y 84.2 LOCTC), como por los fallos previos de inadmisibilidad e inaplicabilidad dictados para la misma gestión judicial, según se verá a continuación. Como los efectos de los procesos de inaplicabilidad incoados con anterioridad a

${ }^{6}$ Véanse panorámica y significativamente los estudios de BlaSCO (1994), pp. 40 y ss.; BoCANEGra (1981), pp. 514 y ss.; él mismo (1982); Rodeville-Hermann (1989), pp. 1760 y ss.; Vogel (1988), pp. 568-627; y ZaGrebelsKy (1988), pp. 327 y ss. Para Chile son importantes las tempranas reflexiones de Aldunate, (1993), pp. 355-359; y lo que señala ZaPaTa (2008) pp. 363-367.

${ }^{7}$ Véase NogueIra (2006), pp. 99-101. 
la reforma de la Ley No $20.050^{8}$ y los efectos de los procesos de control previo en los procesos de inaplicabilidad no pueden ser profundizado en este ensayo ${ }^{9}$, a continuación me limitaré a reseñar el efecto de las decisiones de inadmisibilidad, de desestimación y de acogimiento dentro del proceso de inaplicabilidad y dentro de la gestión judicial en que éste incide.

\section{LOS EFECTOS DE LAS DECISIONES DE INADMISIÓN A TRÁMITE Y}

DE LAS DECISIONES DE INADMISIBILIDAD

El proceso de inaplicabilidad puede cerrarse anticipadamente mediante dos formas que no suponen, o no deben suponer, un pronunciamiento de fondo sobre el asunto sometido a la decisión del Tribunal Constitucional. Se trata de decisiones interlocutorias que no son de mérito y que, con distinta intensidad, abortan la formación del proceso constitucional. En particular, se exponen a continuación las resoluciones de inadmisión a trámite y las sentencias de inadmisibilidad propiamente tales.

\section{A. Admisión a tramitación y examen previo de admisibilidad: efectos de la sentencia simple de inadmisión a tramitación}

El examen de admisibilidad encuentra su fundamento en la propia Constitución. De acuerdo con el art. 93 de la Constitución, "[c]orresponderá a cualquiera de las salas del Tribunal declarar, sin ulterior recurso, la admisibilidad de la cuestión siempre que verifique la existencia de una gestión pendiente ante el tribunal ordinario o especial, que la aplicación del precepto legal impugnado pueda resultar decisivo en la resolución de un asunto, que la impugnación esté fundada razonablemente y se cumplan los demás requisitos que establezca la ley”. Esta norma es complementada por los arts. 82 y 84 de la LOCTC, que en esta parte parecen duplicar el único examen a que se refiere la Constitución. En efecto, el citado art. 82 LOCTC establece un control previo al examen de admisibilidad, llamado por el Tribunal y la doctrina como de "admisión a trámite" 10 , de carácter

\footnotetext{
${ }^{8}$ Véase al respecto el inciso $2^{\circ}$ del artículo $1^{\circ}$ transitorio de la LOCTC: "Los recursos de inaplicabilidad resueltos por la Corte Suprema o que se hubieren tenido por desistidos o abandonados, con anterioridad al 26 de febrero del año 2006, no podrán presentarse ante el Tribunal Constitucional en ejercicio de la facultad que concede el número $6^{\circ}$ del artículo 93 de la Constitución Política”. Con relación a esos procesos, véase la STC Rol No 797, 11 de diciembre de 2007, considerandos $10^{\circ}-12^{\circ}$.

${ }^{9}$ Véanse a título referencial los casos resueltos en las SSTC roles No 1406, 31 de diciembre de 2009, considerandos $7^{\circ}$ y ss.; y No 589,21 de agosto de 2007 , considerandos $16^{\circ}$ y $45^{\circ}$.

${ }^{10}$ PICA (2010), p. 243. Según Pica esta norma sigue al antiguo artículo 39 LOCTC, previo a la reforma de la Ley No 20.381.
} 
formal y mediante el cual se revisa la legitimación procesal, la suficiencia de la documentación requerida por la ley y la fundamentación del requerimiento (arts. 79 y 80 LOCTC).

Este examen de admisión a trámite no tenía sustento en el Mensaje del Proyecto y fue añadido en el primer trámite a raíz de una indicación presidencial, que fue aprobada sin mayor discusión por el Senado ${ }^{11}$. Tampoco fue objeto de objeciones en la fase de control previo de constitucionalidad ${ }^{12}$. Aunque no constan los fundamentos explicativos de esta norma, es posible sospechar que la preterición involuntaria, de parte de los redactores del proyecto, de las propias normas constitucionales que configuran directamente la primera fase del proceso de inaplicabilidad haya explicado la intercalación de una fase procesal no contemplada por la Constitución. Por otro lado, se hacía necesario formalizar un trámite que, todavía en menor grado que el examen de admisibilidad, revisara los aspectos formales del escrito que plantea la cuestión de inaplicabilidad.

Conforme con la LOCTC, si no se cumple con las exigencias señaladas en los artículos 79 y 80 el requerimiento "no será acogido a tramitación y se tendrá por no presentado para todos los efectos legales". A diferencia de lo que más adelante señala la LOCTC respecto de la sentencia de inadmisibilidad, la resolución de no admisión a trámite se limita a tener el requerimiento por no presentado. Luego, en la medida en que esta sentencia de inadmisión a trámite se limita a cuestiones estrictamente formales, es que ella no produce cosa juzgada y, por lo tanto, no impide que, más adelante en el proceso, el que fue reputado como no requierente pueda intentar la admisión de un nuevo requerimiento de inaplicabilidad. En definitiva, el efecto de la simple inadmisión a trámite es similar al del retiro de la acción, en el sentido que el requerimiento se tiene por no presentado ${ }^{13}$.

\section{B. Examen previo de admisibilidad: efecto preclusivo de la sentencia de inadmisibilidad}

Despejado favorablemente el análisis de admisión a trámite, la LOCTC dispone el examen de admisibilidad propiamente tal (artículos 82 , incisos $3^{\circ}$ y $4^{\circ}$, y 84 ), trámite que se realiza en cuenta por las salas o previa vista con la participación de

\footnotetext{
${ }^{11}$ Vid. Biblioteca del Congreso Nacional (2009), Boletín de indicaciones presentadas durante la discusión general (12 de junio de 2007), p. 264.

12 STC Rol No 1.288, 25 de agosto de 2009.

13 "Mientras no sea declarada su admisibilidad, las cuestiones promovidas ante el Tribunal por los órganos o personas legitimados podrán ser retiradas por quien las haya promovido y se tendrán como no presentadas", art. 46 LOCTC.
} 
las partes si ha llegado a formarse un incidente de admisibilidad. El efecto de la declaración de inadmisibilidad, que no admite recurso alguno, es escuetamente explicado en el art. 84 LOCTC, que se limita a señalar que "el requerimiento se tendrá por no presentado, para todos los efectos legales".

Dado que la decisión de inadmisibilidad es, en cierto sentido, una no decisión, no parecen haber buenas razones para colegir de esta resolución no sustantiva un efecto similar al de la fuerza de cosa juzgada. En efecto, se trata de una decisión que no resuelve ningún conflicto ni se pronuncia sobre ninguna petición, razones suficientes para negarle el efecto de cosa juzgada ${ }^{14}$. Fuera del campo natural de los controles de admisibilidad, que es el de las acciones y recursos sometidos a un plazo, la sentencia de inadmisibilidad propia de la inaplicabilidad no afecta la oportunidad para deducir la acción. Si esta última estuviese sujeta a un plazo, la inadmisibilidad conduciría a la natural preclusión procesal de la acción por el transcurso del plazo. Sin embargo ello no es así, puesto que la inaplicabilidad puede interponerse "en cualquier oportunidad procesal", mientras se encuentre pendiente la gestión judicial.

La deficiente construcción normativa, tanto a nivel constitucional como legal, de los efectos (y, por lo tanto, también de los fines) de la declaración de inadmisibilidad, ha llevado al Tribunal Constitucional a definir sus efectos desde dos perspectivas. La primera es la propia Constitución, que excluye cualquier recurso contra la sentencia que resuelve el control de admisibilidad, y la segunda es la institución procesal de la preclusión. Así, en Cifuentes Olea el Tribunal (STC Rol No 1.282 de 18 de diciembre de 2008) estimó que la pretensión de la requirente renovaba una discusión cerrada mediante una "sentencia interlocutoria" anterior de inadmisibilidad. Dado que el texto constitucional señala "corresponderá a cualquiera de las salas del Tribunal declarar, sin ulterior recurso, la admisibilidad de la cuestión", la inadmisibilidad de la pretensión es argumentada como consecuencia del proceso de única instancia:

"40. Que, efectuado el examen del requerimiento deducido, se advierte que éste importa, en el hecho, un recurso que intenta dejar sin efecto la sentencia interlocutoria dictada el 4 de noviembre del año en curso, que declaró inadmisible la misma acción de inaplicabilidad por inconstitucionalidad presentada ante esta Magistratura Constitucional por la señora Sonia Cifuentes Olea, con fecha 28 de octubre de 2008 -Rol 1265-08-INA-;

$5^{\circ}$. Que, en efecto, en la causa individualizada precedentemente esta Sala del Tribunal Constitucional declaró inadmisible el requerimiento deducido por la actora de estos autos, que perseguía la declaración de inaplicabilidad del mismo precepto legal que

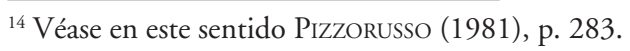


impugna en este caso -artículo 38 ter de la Ley No 18.933-y respecto de idéntica gestión pendiente -recurso de protección Rol de Ingreso No 8798-2008, de la Corte de Apelaciones de Santiago-. Asimismo, en la acción deducida en aquella oportunidad la requirente planteó que el conflicto de constitucionalidad que eventualmente se produciría por la aplicación de la disposición legal mencionada en el caso sub lite, se relaciona con los derechos y garantías que se reconocen en los numerales $2^{\circ}, 9^{\circ}$ y $24^{\circ}$ del artículo 19 de la Ley Fundamental. La distinta formulación que se presenta en el texto de la acción bajo examen, sobre las consideraciones de derecho en las que ella se apoya no cambia la circunstancia de tratarse de la misma pretensión ya declarada inadmisible;

$6^{\circ}$ Que la normativa citada en el considerando $3^{\circ}$ de esta sentencia es clara en establecer que no cabe deducir recurso alguno en contra de las resoluciones que dicte la Sala en ejercicio de la atribución que se le asigna en la materia" ${ }^{15}$.

Según la interpretación transcrita, el requerimiento que vuelve a plantear la cuestión ya declarada inadmisible entraña una suerte de recurso excluido por la propia Constitución.

Como la norma constitucional puede admitir otra interpretación, cual es que la exclusión recursiva se limita a la declaración de admisibilidad (que teóricamente podría no comprender la de inadmisibilidad), ha sido preciso reforzar el efecto impeditivo de la sentencia de inadmisibilidad con una argumentación adicional y ésta se ha construido en torno a la institución de la preclusión procesal. Este esfuerzo dogmático se concreta en un fallo del año 2009, que emparenta los efectos de nuestra inadmisibilidad con la de alguna de sus lejanas parientes europeas. En efecto, como lo recuerda Alessandro Pizzorusso "característica fundamental de las decisiones de desestimación y de las de inadmisibilidad, es la de no constituir cosa juzgada y por ello permitir la nueva proposición de la cuestión; únicamente en el ámbito del juicio a quo, se determina una preclusión que impide la nueva propuesta, a menos que se deduzcan motivos nuevos"16.

El fallo que recibe "pretorianamente" 17 la doctrina de la preclusión es anterior a la reforma de la LOCTC y recae en el asunto Cortés Alarcón (STC Rol No 1.311, de 2 de abril de 2009). En esa oportunidad el Tribunal aplicó la preclusión para sostener que, una vez ejercida la acción constitucional, ésta no puede renovarse sucesivamente en la misma gestión judicial. Para este fallo resultaba "determinante analizar la institución procesal de la preclusión en el sistema procesal nacional y

\footnotetext{
${ }^{15}$ STC Rol No $1.282,18$ de diciembre de 2008.

${ }^{16}$ Pizzorusso (1981), p. 283.

${ }^{17}$ ZÚNíIGA (2010) p. 334.
} 
cómo opera en este proceso constitucional"18. A partir de la mentada institución el Tribunal "desprende que el requirente tiene la carga procesal que le exige plantear todas las infracciones constitucionales en una misma y sola oportunidad, como única forma de producir certeza en los derechos que invoca y de obtener de una vez el pronunciamiento del Tribunal sobre los mismos. El requirente tiene la facultad de hacer uso de este derecho, pero debe hacerlo en el contexto de lo que exige un proceso racional y justo. En consecuencia, la carga es un imperativo del propio interés. Quien tiene sobre sí la carga procesal se halla compelido implícitamente a realizar el acto previsto en la única oportunidad en que puede hacerlo" ${ }^{19}$. De este modo, la declaración de inadmisibilidad genera una suerte de "preclusión por consumación”, que obliga a dicho órgano a inadmitir los requerimientos posteriores.

La preclusión es explicada por el Tribunal del siguiente modo:

"Que especial importancia tiene, para estos efectos, la preclusión por consumación. Si se hace uso del derecho, no puede luego repetirse el acto. Como su nombre lo indica, es la pérdida de la facultad por su uso (...) [E]n consecuencia, debe concluirse que en el proceso que constituye la gestión pendiente este es el segundo requerimiento de inaplicabilidad por inconstitucionalidad interpuesto por la misma materia y fundamento, por lo cual debe ser desestimado, toda vez que al haber consumado en el requerimiento anterior su derecho, éste precluyó" ${ }^{20}$.

En definitiva, de acuerdo con los criterios señalados (todos anteriores, como se dijo, a la nueva versión de la LOCTC) la sentencia de inadmisibilidad genera un efecto vinculante para la parte que dedujo la acción y, naturalmente, para el propio Tribunal Constitucional. Este efecto, que es absoluto, deriva del agotamiento por consumación de una acción que reunió los mínimos formales para ser admitida a trámite pero no los máximos para ser declarada admisible.

Extrapolando la propia doctrina del Tribunal Constitucional ${ }^{21}$, puede decirse que en este caso la preclusión obra como sanción que limita el derecho de acceso expedito a la justicia constitucional. Luego, para que ella opere es preciso un cuidado escrutinio que sea capaz de dar expresa cuenta de la concurrencia copulativa

\footnotetext{
${ }^{18}$ STC Rol No 1.311 , de 2 de abril de 2009, considerando $6^{\circ}$.

${ }^{19}$ STC Rol No 1.311, de 2 de abril de 2009, considerando $9^{\circ}$.

${ }^{20}$ STC Rol No 1.311 , de 2 de abril de 2009 , considerandos $14^{\circ}$ y $15^{\circ}$.

${ }^{21}$ Véanse especialmente la STC Rol No $1.182,18$ de noviembre de 2008 , considerandos $20^{\circ}-21^{\circ}$, con relación a lo fallado en el control preventivo de la que fue la Ley No 20.381, adecuatoria de la LOCTC, STC Rol No 1.288 , de 25 de agosto de 2009 , considerando $26^{\circ}$.
} 
de los siguientes tres requisitos: (i) la identidad de las partes, (ii) la identidad de la gestión, y (iii) la identidad de la pretensión y su fundamento.

\section{a) Las condiciones del efecto preclusivo: identidad de partes}

El efecto preclusivo se limita a la parte que ejerció su derecho a la acción. Extender la sanción a quienes no son parte en la falta constituiría una denegación de justicia infractora de los principios del debido proceso y, particularmente de la personalidad de las sanciones procesales. No debe olvidarse, a este respecto, que las normas rectoras del proceso justo y racional también obligan al Tribunal Constitucional en el ejercicio de sus funciones jurisdiccionales, por lo que toda limitación al derecho constitucional de acción frente al Tribunal Constitucional debe ser sesudamente justificada ${ }^{22}$.

Por cuanto concierne a las otras partes del proceso, éstas podrán siempre requerir la declaración de inaplicabilidad. Incluso más, en la medida en que exista pluralidad de partes, los efectos del fallo estimatorio de fondo hasta podrían llegar a beneficiar a la parte que fue sancionada con la inadmisibilidad. Ejemplo de lo anterior es el primer fallo de la conocida saga de inaplicabilidades seguidas contra el turno de los abogados. Como se sabe, la sentencia estimatoria STC Rol No 755, de 31 de marzo de 2008 surtió sus efectos en el recurso Rol No 6.6262006, Toloza con Juez de Familia de Osorno, conocido por la Corte Suprema y fallado por ésta el 24 de junio de 2008. Pues bien, en dicho recurso de protección también figuraba como parte el abogado Franklin Gallegos, quien un año antes había requerido la inaplicabilidad del mismo precepto $^{23}$, en la misma causa y prácticamente por los mismos motivos ${ }^{24}$. Si bien el requerimiento de Gallegos fue declarado inadmisible $e^{25}$, no habían razones procesales para que los efectos del ulterior proceso de inaplicabilidad abierto por otra de las partes del mismo proceso no le fueran extendidos, del mismo modo en que le afectaría el resultado de la gestión judicial principal. La unidad del proceso exigía que la gestión judicial, en este caso un recurso de apelación, se resolviera indivisiblemente. En otras palabras, la preclusión que pudo generar la inadmisibilidad del primer requerimiento a lo

\footnotetext{
${ }^{22}$ Véase Nico (2007), pp. 168-170.

${ }^{23}$ En Gallegos había pedido además la inaplicabilidad del art. 598 del Código Orgánico de Tribunales.

${ }^{24}$ Si bien Gallegos enumeraba más infracciones que Toloza, todas las normas constitucionales señaladas por el último estaban comprendidas en el requerimiento del primero.

${ }^{25}$ La diferencia entre ambos requerimientos radicaba, más bien, en su estilo. El inadmisible planteó el conflicto en términos abstractos, mientras que el admisible lo hizo de un modo concreto. Véase la STC Rol No 733,21 de marzo de 2007.
} 
sumo terminó con un proceso constitucional, pero no pudo impedir la iniciación de otro. En este último, aunque no consta que así lo haya hecho, incluso es muy discutible que el primer requirente no haya tenido legitimación para actuar como parte interesada ${ }^{26}$.

\section{b) Las condiciones del efecto preclusivo: identidad de gestión}

La identidad de la gestión exige un doble análisis. Es preciso que la gestión considerada en su totalidad y, según los casos, en su particularidad sea la misma. El primer análisis de la totalidad de la gestión es más o menos simple, él implica que el efecto preclusivo no opera para procesos distintos. El análisis de la particularidad es más complejo y resulta obligado cuando ha cambiado sustancialmente el estadio procesal de la gestión. En efecto, cuando las diferencias entre las fases procesales de uno y otro requerimiento son tan notorias que el conflicto de constitucionalidad ya no puede ser el mismo, el efecto preclusivo de la primera inadmisibilidad no puede impedir la sustanciación de un segundo proceso de inaplicabilidad. Este segundo análisis es el único que permite advertir si el caso es el mismo o si ha padecido alguna variación sustancial. Así por ejemplo, si un requerimiento es declarado inadmisible porque a juicio de la Sala el requirente no puede ser juzgado dado que se encuentra fuera del territorio nacional ${ }^{27}$, no podría invocarse la preclusión cuando la gestión principal avance al estado en que el requirente sí pueda ser juzgado porque está en el territorio nacional o porque por cualquier motivo ha sido posible procesarlo en ausencia. Igualmente, si el requerimiento es declarado inadmisible porque, a juicio del Tribunal, el precepto legal no será decisivo atendido que no existe el agravio que la gestión judicial principal pretende reparar, el efecto preclusivo de la inadmisibilidad no podría declararse si luego se demuestra que dicha inexistencia no es efectiva ${ }^{28}$.

\footnotetext{
${ }^{26}$ Por lo tanto, conforme con el art. 79 LOCTC el tribunal de la gestión igualmente deberá haber notificado a esa parte de la presentación del nuevo requerimiento, en el cual será parte activa.

${ }^{27}$ STC Rol No 1482, 21 de octubre de 2009, considerando $14^{\circ}$. Este caso, que se refería a la investigación penal seguida en contra de un ciudadano extranjero acusado del delito de sodomía, tuvo connotación pública nacional.

${ }^{28}$ STC Rol No 2039, 20 de septiembre de 2011. La inaplicabilidad fue declarada inadmisible por una anómala intervención en el asunto de fondo: "conforme a los antecedentes que obran en el proceso, a los documentos acompañados por Aguas Andinas S.A. (fojas 186) y a lo señalado en estrados por el abogado que alegó en su representación, al recurrente de protección se le restituyó el servicio de agua potable por la aludida empresa el día 12 de julio de 2011. En consecuencia, la recurrida de protección ha alegado que tanto la acción de protección que constituye la gestión sub lite como la presente acción de inaplicabilidad habrían perdido oportunidad, debiendo esta última ser declarada inadmisible. Además, adujo Aguas Andinas que en la especie concurría la causal de inadmisibilidad del $\mathrm{N}^{\circ} 6^{\circ}$ del artículo 84 de la Ley $\mathrm{N}^{\circ} 17.997$, Orgánica
} 


\section{c) Las condiciones del efecto preclusivo: identidad de pretensión y de su fundamento}

La pretensión se centra en el precepto legal, comprendido como unidad lingüística, cuya inaplicación se solicita al Tribunal. El fundamento es la razón jurídica de la pretensión, indisociable de las particularidades del caso que exige el control concreto y que debe ser detalladamente presentada al Tribunal para el análisis previo de admisibilidad. Mediante esta fundamentación, el requirente razona en torno al especial conflicto de constitucionalidad que somete a la decisión del Tribunal y que no es otro que la generación de un efecto no querido por la Constitución merced de la aplicación de un precepto legal en una gestión judicial pendiente.

Relatando la identidad que se produce cuando sólo hay ligeros cambios en la fundamentación de las acciones, el Tribunal ha afirmado:

" $6{ }^{\circ}$. Que, en efecto, se advierte que el requerimiento interpuesto en la especie importa, en el hecho, un recurso que intenta dejar sin efecto la sentencia interlocutoria dictada el 9 de marzo de 2010 (...) que declaró inadmisible una anterior acción de inaplicabilidad por inconstitucionalidad (...) Asimismo, en la acción deducida en aquella oportunidad el requirente planteó el mismo conflicto de constitucionalidad que hoy vuelve a someter a esta Magistratura a través del libelo materia de este proceso (...).

$7^{\circ}$. Que la distinta formulación que se presenta en el texto de la acción bajo examen, en el que se añaden normas legales al objeto de la impugnación constitucional e incluso variando, aunque levemente, algunos argumentos de derecho en los que se apoya cada requerimiento, no cambia la circunstancia de que se está frente a la misma pretensión, fundada en el mismo conflicto constitucional, que ya fue declarada inadmisible por este Tribunal;

$8^{\circ}$ Que lo expresado lleva a concluir que si la normativa transcrita en esta sentencia es clara en establecer que no cabe deducir recurso alguno en contra de las resoluciones que dicte la Sala en ejercicio de la atribución que se le asigna en la materia, el intento del actor por burlarla, a través de la interposición de un requerimiento de inaplicabilidad que sólo es nuevo en apariencia, produce el efecto de estimar que la acción deducida en

\footnotetext{
Constitucional de esta Magistratura, esto es, que el requerimiento carecería de fundamento plausible (...) La circunstancia de la reposición del servicio de agua potable en la fecha indicada, no ha sido controvertida en autos por el señor Reyes Barraza (...) Que, conforme a lo expuesto, esta Sala ha llegado a la convicción de que -habiendo la recurrida de protección restituido el servicio de agua potable al recurrente- los preceptos legales impugnados no serán decisivos para la resolución de la gestión en que incide el presente requerimiento, ya que han perdido oportunidad en su aplicación" (fundamentos $6^{\circ}$ y $7^{\circ}$ ). A pesar del proceder invasivo de la Primera Sala del Tribunal (con el voto en contra de los ministros Navarro y Suárez), la Corte de Apelaciones posteriormente rechazó el recurso de protección por razones no muy distintas a las razonadas por el Tribunal, véase la sentencia de la Corte de Apelaciones de Santiago, 14 de noviembre de 2011, Rol No 101-2011.
} 
estos autos no contiene una impugnación razonablemente fundada y, por consiguiente, debe ser declarada inadmisible"29.

III. LOS EFECTOS DE LA SENTENCIA DE INAPLICABILIDAD DENTRO DEL PROCESO: SENTENCIA DESESTIMATORIA DE INAPLICABILIDAD Y EFECTO DE COSA JUZGADA

\section{A. Los efectos para el Tribunal Constitucional dentro de la gestión en que incide el fallo}

La sentencia que rechaza la cuestión de inaplicabilidad genera, respecto del vicio que sustenta la decisión, un efecto impeditivo dentro del proceso en que ella incide. De acuerdo con el art. 90 LOCTC, la cuestión "no podrá ser intentada nuevamente, por el mismo vicio, en las sucesivas instancias o grados de la gestión en que se hubiere promovido". En su versión original, la norma recién transcrita omitía la referencia a la identidad del vicio ${ }^{30}$. Esta última exigencia de identidad se agregó para evitar una injusta o excesiva ampliación de la cosa juzgada y condicionar el efecto impeditivo de la sentencia desestimatoria a la necesaria coincidencia entre los fundamentos de la primera acción y la fundamentación de los requerimientos posteriores ${ }^{31}$.

La LOCT se refiere sucintamente al "vicio", sin explicitar el lugar donde éste se encuentra. La cuestión radica en discernir si se trata de los vicios señalados en el requerimiento o en la motivación de la sentencia. Si se tratase de lo primero, el efecto impeditivo de la cosa juzgada estaría limitado a la identidad de la causa de pedir. Respondiendo esta pregunta antes de la entrada en vigencia de la LOCTC VEGA y ZÚNIGA anticiparon que "la cosa juzgada que genera esta clase de sentencias impide al actor de la acción de inaplicabilidad desestimada, renovar su pretensión ante el Tribunal Constitucional, respecto de la misma gestión pendiente y por el mismo capítulo de impugnación" 32 . El énfasis de la comparación estaría puesto entonces en las partes, la gestión y el fundamento de la impugnación.

\footnotetext{
${ }^{29}$ STC Rol No 1671, 21 de abril de 2010.

${ }^{30} \mathrm{El}$ texto del Mensaje rezaba del siguiente modo: "Artículo 47 L.- Resuelta la cuestión de inaplicabilidad por el Tribunal Constitucional, no podrá ser intentada nuevamente en las sucesivas instancias o grados de la gestión en que se hubiere promovido". La frase "por el mismo vicio" fue intercalada por la Comisión de Constitución, Legislación, Justicia y Reglamento en el primer trámite (primer informe), véase Biblioteca del Congreso Nacional (2009), p. 120.

${ }^{31}$ Esta limitación hace que la doctrina se refiera a la cosa juzgada relativa, "que posibilita el replanteamiento de la cuestión de constitucionalidad ya decidida en sentencia por el órgano de jurisdicción constitucional, por razones diferentes a las ya analizadas", NoGUEIRA (2009), p. 484.

32 ZúNiga y Vega (2006), p. 155.
} 
Constatada la coincidencia señalada, después de un "examen particularmente estricto" 33 , la cosa juzgada obliga al Tribunal a declarar inadmisible el requerimiento, agregándose al proceso de inaplicabilidad una causal de inadmisibilidad distinta a las codificadas en el art. 84 LOCTC $^{34}$. De este modo, la cosa juzgada tendría el carácter de formal, afectaría sólo al requirente y operaría de un modo autónomo y distinto a las causales señaladas en el art. 84 LOCTC, impidiendo que el Tribunal recurriese, como lo hizo antes de la nueva LOCTC, a la sola falta de fundamento plausible del requerimiento como causal de inadmisibilidad del requerimiento de inaplicabilidad ${ }^{35}$. Con todo, en la medida en que el requirente no justifique sufi-

33 "[E]l análisis destinado a decidir si existe cosa juzgada respecto de una acción de inaplicabilidad debe ser particularmente estricto, porque, tal como ha precisado este Tribunal, en anteriores pronunciamientos (Roles Nos. 478, 546, Capítulo I, 473, 517, 535, 596 y 767), las características y circunstancias del conflicto que ella envuelve han adquirido, en la actualidad, una relevancia mayor de la que debía atribuírseles antes de 2005. En efecto, hoy la decisión jurisdiccional de esta Magistratura ha de recaer en la conformidad o contrariedad con la Constitución que la aplicación del precepto impugnado pueda tener en el caso concreto sub lite, lo que refuerza el carácter concreto de esta acción”, STC Rol No 790, 11 de diciembre de 2007, considerando $12^{\circ}$. En este caso la cosa juzgada alegada, y en definitiva desechada, emanaba supuestamente de un fallo de inaplicabilidad emanado de la Corte Suprema el año 1999.

${ }^{34}$ No debería confundirse la declaración de inadmisibilidad por cosa juzgada generada a partir de una sentencia de inaplicabilidad, con la cosa juzgada generada en procesos de control preventivo. A esta última parecen referirse los artículos 71 y 84 LOCTC. El primero establece que "[d]eclarado por el Tribunal que un precepto legal impugnado de conformidad a este Párrafo es constitucional, no podrá ser declarado posteriormente inaplicable por el mismo vicio materia del proceso y de la sentencia respectiva"; el segundo señala que "[p] rocederá declarar la inadmisibilidad en los siguientes casos: (... ) "2. Cuando la cuestión se promueva respecto de un precepto legal que haya sido declarado conforme a la Constitución por el Tribunal, sea ejerciendo el control preventivo o conociendo de un requerimiento, y se invoque el mismo vicio que fue materia de la sentencia respectiva". Si se examina la historia de la Ley, es posible observar que el sentido original de ambas normas era compatibilizar el control preventivo con el represivo. En el Mensaje se lee: "Considerando que en su nueva configuración, el Tribunal concentra el control preventivo y represivo de preceptos legales, el proyecto establece que si el Tribunal resolvió en su control preventivo que un precepto legal determinado o un proyecto de ley era constitucional, no puede declararlo inaplicable con posterioridad por el mismo vicio que fue materia de la sentencia. Con eso se asegura la debida coordinación para el ejercicio de ambas atribuciones", Biblioteca del Congreso Nacional (2009), p. 16.

${ }^{35}$ STC Rol No 979, 29 de noviembre de 2007. En los considerandos $5^{\circ}$ y $6^{\circ}$ de este fallo se lee: "debe concluirse que la presentación de fojas uno no cumple con la exigencia constitucional de encontrarse fundada razonablemente. En efecto, no puede considerarse como razonablemente fundada la acción intentada en la especie, si resulta evidente que el conflicto de constitucionalidad que se plantea coincide con el que, en su oportunidad, ya fue resuelto por esta Magistratura al conocer del requerimiento de inaplicabilidad (...) interpuesto por el mismo señor Pineda Peña en contra de la aplicación del artículo 299, № 3, del Código de Justicia Militar, en el proceso judicial en el que aquél fue condenado como autor del delito que esa norma establece, por sentencia dictada por el tribunal competente; "[q]ue la circunstancia referida precedentemente no se altera por el hecho de que ahora se intente por el actor ampliar y complementar el cuestionamiento de fondo ya resuelto por este Tribunal Constitucional, añadiendo al artículo 299, № 3, antes cuestionado, referencias a los artículos 431 y 433 del Código de Justicia Militar y aludiendo a lo sentenciado por esta Magistratura en el Rol 781, que recayó en un caso concreto diverso". Con relación a este fallo véase la STC Rol No 468, 9 de diciembre de 2006. 
cientemente las diferencias entre el caso ya fallado y la nueva pretensión, existirá un parentesco natural entre la cosa juzgada y la falta de fundamento.

Este modo de entender los efectos de la sentencia desestimatoria tiene una consecuencia procesal para la redacción de la sentencia: obliga al Tribunal a pronunciarse sobre todas las posibles infracciones denunciadas por el requirente. En efecto, a diferencia de lo que acontece con las sentencias estimatorias de inaplicabilidad ${ }^{36}$, una técnica procesal adecuada y ajustada a las exigencias del debido proceso exige la completa congruencia entre la acción y la sentencia, de modo que para rechazar un requerimiento es preciso que el Tribunal se pronuncie sobre todas las pretensiones y particularmente todos los argumentos presentados por las partes ${ }^{37}$.

\footnotetext{
36 "Que, en el evento de concluirse que, en virtud de alguna de las razones constitucionales invocadas, la aplicación del precepto legal a la gestión pendiente resulta contraria a la Carta Fundamental, se hará innecesario, en esta oportunidad, analizar las demás causales de inaplicabilidad invocadas respecto del mismo precepto legal. Este modo de razonar, ya asentado en nuestro medio jurídico, se sustenta en el hecho de que resulta innecesario e inútil entrar a considerar si un precepto, cuya inaplicabilidad ya se ha concluido por contradecir una norma constitucional, debe ser declarado inaplicable además por ser contrario a otro precepto de la Carta Fundamental. Al efecto, debe tenerse presente que esta sentencia de inaplicabilidad sólo produce efectos relativos y que un nuevo análisis de un precepto ya considerado inaplicable por un motivo, no podría arribar a ninguna conclusión útil para la requirente", STC Rol No 747/774, 31 de agosto de 2007. Este fundamento de mayoría no fue compartido por la Ministra Marisol Peña, cuya prevención es pertinente transcribir en su totalidad: "PRIMERO: Porque, a diferencia de lo que se afirma en los considerandos mencionados, esta previniente no concuerda en que la declaración de inaplicabilidad del o de los preceptos legales cuestionados por un determinado vicio de inconstitucionalidad hace innecesario examinar si la aplicación de los mismos, en idéntica gestión, podría vulnerar otros preceptos constitucionales". "SEGUNDO: Que la razón de esta prevención radica en que el recurso de inaplicabilidad por inconstitucionalidad ha sido instituido por el Constituyente como una forma de defensa de la supremacía de la Constitución, de forma de 'impedir que una ley contraria a la Carta Fundamental surta efectos' (Actas Oficiales de la Comisión de Estudio de la Nueva Constitución. Sesión No 286, 21 de abril de 1977, pág. 989). De ello puede colegirse que el examen que ha de realizar el Tribunal Constitucional, que hoy es el órgano competente para declarar la inaplicabilidad, debe referirse a la vulneración integral que la supremacía constitucional pueda experimentar por la aplicación del o de los preceptos legales cuestionados en su aplicación a la gestión específica de que se trata. No basta, en consecuencia, que el juicio sobre la constitucionalidad de las normas impugnadas se circunscriba al análisis de una sola infracción inconstitucional, prescindiendo de las otras que el propio requirente haya señalado y que el tribunal debe asimismo examinar para decidir si también transgreden la Carta Fundamental en su aplicación al caso concreto". "TERCERO: Que la conclusión consignada precedentemente se apoya, al mismo tiempo, en lo dispuesto en el artículo 39, inciso primero, de la Ley No 17.997, Orgánica Constitucional del Tribunal Constitucional, expresamente aplicable a la tramitación del presente requerimiento de inaplicabilidad, según dispone la resolución de fojas 21 y siguiente de estos autos. Conforme a esa norma, '(en el requerimiento) se señalará en forma precisa la cuestión de constitucionalidad y, en su caso, el vicio o vicios de inconstitucionalidad que se aducen, con indicación de las normas que se estiman transgredidas'. En concepto de esta previniente, no tendría sentido que el requirente se esforzara en plantear la infracción integral que aprecia al principio de supremacía constitucional en la gestión pendiente de que se trata si, en definitiva, el Tribunal sólo examinara alguno de los vicios invocados" (cursivas en el original).

${ }^{37}$ En este sentido, STC Rol No 968, 9 de julio de 2008, considerando $7^{\circ}$.
} 
Una facultad del Tribunal que podría llamar a confusión es aquella que permite al Tribunal agregar nuevos motivos de infracción constitucional. Como se sabe, en sede de inaplicabilidad el vicio se configura preliminarmente a partir del modo en que las partes (art. 80 LOCTC) plantean el conflicto en el texto del requerimiento. Este último instrumento debe contener el "fundamento plausible" de la acción (arts. 93.11 CPR y 84 LOCTC) expresado en "una exposición clara de los hechos y fundamentos en que se apoya y de cómo ellos producen como resultado la infracción constitucional" y en una relación del "o los vicios de inconstitucionalidad que se aducen, con indicación precisa de las normas que se estiman transgredidas" (art. 80 LOCTC). A partir de dicho requerimiento el Tribunal define la forma en que se produce la aplicación jurisdiccional contraria a la Constitución (art. 93.6 CPR) o, en lo que aquí importa, explica el porqué no se produce una infracción a la Constitución. Excepcionalmente y por razones fundadas, el Tribunal puede pronunciarse sobre "fundamentos constitucionales distintos a aquellos que han sido invocados por las partes en la litis" (art. 88 LOCTC). Esta facultad, sin embargo, tiene una peculiaridad importante: ella no libera al Tribunal del deber de pronunciarse respecto de todas las alegaciones de las partes y, en lo que aquí interesa, como facultad excepcional opera sólo si el Tribunal resuelve "declarar la inconstitucionalidad [sic] de las normas cuestionadas". Para el caso que nos ocupa, esto es el rechazo del requerimiento, esta atribución no es aplicable y por lo tanto jamás la sentencia debería descartar la existencia de un vicio no alegado por las partes.

\section{B. La distinción entre infracción constitucional y vicio de inconstitucionalidad}

La LOCTC, en su art. 80, hace referencia separada a la "infracción constitucional" y al o los "vicios de constitucionalidad"38, distinción que podría llevar a entender que se trata de dos conceptos distintos. Ello, sin embargo, no es así. En efecto, en su primera formulación, en el texto del Mensaje, el proyecto no incluía la referencia a la "infracción constitucional". Esta última frase fue añadida en el segundo trámite constitucional merced de una indicación del Senador Romero $^{39}$. Esta indicación, cuyos fundamentos explícitos no son conocidos, parecía

\footnotetext{
${ }^{38}$ El inciso primero señala: "[e]l requerimiento de inaplicabilidad, sea promovido por el juez que conoce de la gestión pendiente o por una de las partes, deberá contener una exposición clara de los hechos y fundamentos en que se apoya y de cómo ellos producen como resultado la infracción constitucional. El segundo agrega "[d] eberá indicar, asimismo, el o los vicios de inconstitucionalidad que se aducen, con indicación precisa de las normas constitucionales que se estiman transgredidas"

${ }^{39}$ Indicación No 75, segundo trámite, Biblioteca del Congreso Nacional (2009), p. 263. El texto de la indicación sustitutiva era sustancialmente idéntico al vigente.
} 
querer ajustar el texto legal a la fórmula constitucional de la aplicación contraria a la Constitución (art. 93.6 CPR). Sin embargo, como la referencia al "vicio de inconstitucionalidad" se mantuvo en el texto final, el efecto final logrado no fue sino el de la simple reiteración.

La impropiedad de la reiteración es en todo caso explicable, dado que es muy posible que a julio de 2006, data de las indicaciones presentadas en el Senado, los legisladores no sospecharan el rumbo que tomaría la inaplicabilidad durante el primer año de vigencia de la reforma de 2005. Muy por el contrario, a partir del lenguaje utilizado por los redactores de la Ley No 20.281 (D. Of. de 28 de octubre de 2009) es posible deducir que el texto fue elaborado con el espíritu de la vieja inaplicabilidad, que languidecía conforme se consolidaba jurisprudencialmente, y a espaldas del Congreso, el instituto del control concreto.

\section{Los efectos para los tribunales de la gestión pendiente}

La sentencia desestimatoria devuelve a los tribunales de la gestión la libertad para fallarla en su mérito y de acuerdo con las normas legales impugnadas u otras si ellos estiman que aquéllas no son pertinentes a los hechos del proceso. En la STC Rol No 781 de 2007, el Tribunal explicó este efecto del siguiente modo: "en caso de desecharse por este Tribunal Constitucional la acción de inaplicabilidad intentada, el juez de la instancia recupera en plenitud su facultad para determinar la norma que aplicará a la resolución del conflicto del que conoce, sin que necesariamente deba ella ser la misma cuya constitucionalidad fue cuestionada sin éxito" 40 (cursivas añadidas). Esta última frase es significativa pues hasta su fallo, el proceso de inaplicabilidad pende sobre otro proceso cuya sentencia de término podría basarse en el precepto impugnado. Esta posibilidad, positivamente recogida como exigencia de admisibilidad ${ }^{41}$, se sustenta en la aplicación pretérita del precepto en alguno de los grados de la gestión o en la razonable posibilidad de que aquél lo sea en las etapas posteriores de la gestión.

Así quien ha sido derrotado en sede de inaplicabilidad puede resultar vencedor en la gestión principal por aplicación de otro precepto legal, del mismo precepto legal pero entendido de un modo distinto al planteado en la cuestión de inaplicabilidad o por aplicación de cualquier otro principio jurídico. Del mismo modo,

${ }^{40}$ STC Rol No 781, 27 de septiembre de 2007, considerando $6^{\circ}$.

${ }^{41}$ Me refiero a la exigencia según la cual "el precepto legal impugnado pueda resultar decisivo en la resolución del asunto". Sobre el significado de este requisito de admisibilidad, que naturalmente puede ser revisado en la sentencia de fondo, véanse entre otros Peña (2008), p. 233; Massmann (2009), pp. 280-285; Navarro, (2010), pp. 265-293; y Filloy y Soto (2011), pp. 237 y ss. 
quien obtuvo en la inaplicabilidad puede resultar vencido en la gestión principal. Un buen ejemplo de lo primero se encuentra en el caso Arancibia Tognia, donde después de fracasar en un importante intento por obtener la inaplicabilidad de una supuesta ley penal delegada relativa al hurto de energía eléctrica ${ }^{42}$, el requirente fue absuelto por falta de pruebas en una sentencia que no dedica una sola línea al problema decidido en la inaplicabilidad ${ }^{43}$. Algo parecido sucedió con el asunto del Villar, donde el requirente no pudo obtener la declaración de inaplicabilidad de un precepto de la Ley Antidrogas que lo inhabilitaba para ejercer la función pública ${ }^{44} \mathrm{y}$, sin embargo, obtuvo en la gestión principal la declaración de ilegalidad de una de las resoluciones reclamadas por razones distintas a las evaluadas por el Tribunal Constitucional ${ }^{45}$. Igualmente, un fallo reciente del Juzgado de Letras del Trabajo de Concepción ${ }^{46}$, que había elevado una cuestión de inaplicabilidad que fue desestimada por el Tribunal Constitucional al no reunirse el quórum constitucional ${ }^{47}$, optó por modular la interpretación del precepto legal y no aplicarlo en la gestión que había dado lugar al fallo de inaplicabilidad. En este último caso, el rechazo de la cuestión promovida por el juez cerró una puerta, pero no inhabilitó al juez para encontrar una ventana.

${ }^{42}$ STC Rol No 1191, 19 de mayo de 2009. El requirente solicitaba la declaración de inaplicabilidad del art. 137 del DFL No 1, de 22 de junio de 1982, del Ministerio de Minería, Ley General de Servicios Eléctricos y que corresponde al artículo 215 del Decreto con Fuerza de Ley No 4, del año 2006, del Ministerio de Economía, Fomento y Reconstrucción. Lo interesante del requerimiento, que se fundamentaba en la prohibición que pesa sobre la legislación delegada para no crear delitos, es que tenía precedentes en la justicia ordinaria. La Corte de Apelaciones de Santiago, en sentencia de 7 de diciembre de 2001, Rol No 70.837-2001, ya había resuelto que en la respectiva ley delegatoria "no se concedió autorización al Presidente de la República para dictar disposiciones penales relativas a la sustracción de energía eléctrica y al contemplar ese tipo de normas aquél se excedió en el empleo de la función legislativa que recibió del Parlamento, lo que importa un vicio de ilegalidad que debe ser declarado de oficio, dejándose, por ende, de aplicar la norma del artículo 137 del Decreto con Fuerza de Ley No 1, de 1982, del Ministerio de Minería. 7º) Que, en consecuencia, por no encontrarse sancionada la conducta que se reprocha a la acusada procede, acorde con lo que dispone el artículo 456 bis del Código de Procedimiento Penal, dictar, a su respecto, sentencia absolutoria”. En sentido similar véase la disidencia del Ministro Dahm en el fallo de la Corte de Apelaciones de Santiago de 31 de julio de 2007, Rol No 29.428-2004.

${ }^{43}$ Tribunal de Juicio Oral en lo penal de Valparaíso, 23 de diciembre de 2010, RUC No 0700364853-7 y RIT No 186-2008.

${ }^{44}$ STC Rol No 1133, 18 de noviembre de 2008.

${ }^{45}$ Véase la sentencia de la Corte de Apelaciones de Valparaíso, 16 de diciembre de 2008, Rol No 76-2008.

${ }^{46}$ Juzgado de Letras del Trabajo de Concepción, 13 de diciembre de 2011, RIT I-36-2010. A la fecha que se cerró este trabajo se encontraba pendiente un recurso de nulidad.

${ }^{47}$ STC Rol No 1790, 4 de octubre de 2011. 
Ejemplos de triunfos pírricos en sede de inaplicabilidad hay varios. Uno de ellos es el célebre caso Peña Wassaf, que dio lugar a la numerosa saga de decisiones relativas al art. 38 ter de la Ley de Isapres. No obstante que la STC Rol No 976 de 26 de junio de 2008 declaró inaplicable la tabla de factores de la citada norma, la Corte de Santiago rechazó sin costas la acción de protección en razón de ser inadmisible por extemporánea. A diferencia de Arancibia Tognia, en Peña Wasaffla Corte de Santiago se preocupó de aclarar que lo resuelto no implicaba desobedecer el fallo constitucional:

"[S]e debe tener en consideración que esta Corte ha detectado un vicio formal en cuanto a la interposición del recurso de protección, cual es haber sido interpuesto de manera extemporánea, motivo por el cual ha estimado improcedente pronunciarse sobre el fondo de la acción debatida, y en especial, a lo que dice relación con la aplicación o no del artículo 38 Ter de la Ley de Isapres. Por lo anterior, no debe entenderse el rechazo al presente recurso como un pronunciamiento que afecte a lo resuelto por el H. Tribunal Constitucional”48.

Pueden agregarse a Wasaff algunos casos conocidos relativos a las Isapres, al artículo 2331 del Código Civil o a la ley del Fondo de Crédito Universitario. En todos estos casos, la sentencia de la gestión judicial argumentó el rechazo de las acciones principales por caminos argumentativos distintos a los discutidos por la mayoría del Tribunal en el fallo de inaplicabilidad. Estos casos serán reseñados más adelante, tratando de describir los no siempre fáciles destinos del proceso.

\section{Sobre el efecto vinculante de las sentencias desestimatorias anómalas}

La literatura comparad ${ }^{49}$ y nacional ${ }^{50}$ ha sido pródiga en explicar las múltiples formas que adoptan las decisiones de los tribunales constitucionales. Dentro de esa tipología múltiple es interesante destacar el caso de las sentencias interpretativas, fórmula decisoria que nuestro Tribunal Constitucional utilizaba habitualmente en los controles preventivos ${ }^{51}$ y que, desde la entrada en vigor de la reforma de la Ley No 20.050, ha venido también utilizando para resolver las cuestiones de inaplicabilidad y las de inconstitucionalidad ${ }^{52}$. El espíritu justificativo de estas

\footnotetext{
${ }^{48}$ Corte de Apelaciones de Santiago, 24 de septiembre de 2008, Rol No 4972-2007, considerando $11^{\circ}$.

${ }^{49}$ Véase particularmente la ilustrada explicación de Pizzorusso (1981), pp. 281 y ss.

${ }^{50}$ Por todos, Nogueira, Humberto (2009), pp. 522 y ss.

${ }^{51}$ Véase ZaPATA (2006), pp. 178 y ss.

${ }^{52}$ Véase por primera vez la STC Rol No 681, 26 de marzo de 2007, considerando $8^{\circ}$.
} 
prevenciones en materia de inaplicabilidad no es otro que la extensión del principio de interpretación conforme con la Constitución ${ }^{53}$.

\section{a) Dos ejemplos paradigmáticos: Morrison y Hopp}

En materia de inaplicabilidad hay dos ejemplos paradigmáticos y tempranos de sentencias desestimatorias con declaración de interpretación, figura que pareciera darse con mayor frecuencia en sede penal y procesal penal ${ }^{54}$. Los casos se contextualizan en la jurisprudencia relativa a la interpretación de los delitos de peligro y al microtráfico. En caso Hopp, si bien se rechazó el requerimiento de inaplicabilidad, el Tribunal se permitió añadir algunos criterios relevantes para la interpretación del delito de asociación ilícita. Para el Tribunal, la consideración del delito de asociación ilícita como una infracción de peligro abstracto puede "y conducir paradojalmente a desproteger bienes jurídicos de suyo importantes para la sociedad y el orden constitucional. Por el contrario, interpretar el precepto guiándose por la presunción de legitimidad que emana de los actos del legislador, concordándola con los principios y valores constitucionales, parece razonable y coherente con la protección del orden público y el recto ejercicio del derecho de asociación que la Constitución consagra" " Lo anterior exige estimar la peligrosidad concreta "como elemento del tipo (...) y, por ende, dicha circunstancia debe ser acreditada" 56 .

Siguiendo una línea similar, en Morrison Cristi el Tribunal revisó los posibles modos de interpretar el tipo penal del microtráfico ${ }^{57}$ y descartó acoger la inaplicabilidad precisamente porque existe un modo de comprender la legislación que no produce un efecto contrario a la Constitución. Este modo consiste, grosso modo, en no liberar al órgano acusador de la carga de probar la participación culpable del imputado y, particularmente, el ánimo de traficar. En otras palabras, la sola posesión de las sustancias prohibidas en las cantidades señaladas por la ley, unida a la inactividad probatoria del imputado (que no puede o no quiere acreditar que

\footnotetext{
${ }^{53}$ Véanse para la inaplicabilidad los primeros indicios de la aplicación de este principio en las SSTC roles No 739, 21 de agosto de 2007, considerando $18^{\circ}$; No 747 (774), 31 de agosto de 2007, considerando $40^{\circ}$; No 781, 27 de septiembre de 2007, voto de los Ministros Peña y Fernández Fredes, $6^{\circ}$.

${ }^{54}$ Véanse en el ámbito penal sustantivo la STC No 1.584, 17 de junio de 2010, sobre la interpretación del art. 317 del Código Penal (en el mediático caso del Suplemento nutricional ADN). En el ámbito procesal pueden verse las SSTC roles No 1484, 5 de octubre de 2010 (sobre el modo de interpretar el art. 186 del Código Procesal Penal); No 1.337, 20 de agosto de 2009 y No 1.380, 3 de noviembre de 2009, ambas sobre los arts. 186 y 230 del Código Procesal Penal.

55 STC Rol No 739, 21 de agosto de 2007, considerando $17^{\circ}$.

${ }^{56}$ STC Rol No 739, 21 de agosto de 2007, considerando $18^{\circ}$.

${ }^{57}$ STC Rol No 993, 13 de mayo de 2008, considerando $14^{\circ}$.
} 
se trata de sustancias necesarias para un tratamiento médico o para el consumo personal exclusivo y próximo en el tiempo) no es suficiente para dar por configurado el delito. A contrario sensu, la condena sin la mentada prueba de la parte acusadora representaría un efecto del precepto legal que es contrario a la Constitución. Cabe mencionar que, a la fecha en que se sustanciaba la inaplicabilidad, dicho efecto ya se había producido por lo menos una vez. En efecto, en sentencia de 17 de octubre de 2007 la Corte de Apelaciones de Temuco había anulado un primer fallo absolutorio dictado en favor del futuro requirente de inaplicabilidad. Resolviendo un recurso de nulidad, la Corte de Temuco había estimado que la regla de la Ley No 20.000 sólo invierte el onus probandi y que el Tribunal Oral no podía excusarse en una duda razonable para no dar por configurado el delito y la participación culpable de su autor ${ }^{58}$.

El seguimiento del caso Hopp, a fin de corroborar el impacto real del fallo interpretativo de inaplicabilidad, no ha sido todavía posible. A la fecha en que se escriben estas líneas se encuentra pendiente la extradición del acusado desde Alemania. En cuanto al caso Morrison, el requirente fue absuelto en un segundo juicio por falta de pruebas; en sentencia leída el 9 de julio de 2008, el Tribunal Oral en lo penal de Temuco repitió el mismo criterio que había expuesto el año anterior ${ }^{59}$ : "El Ministerio Público no ha podido acreditar, más allá de toda duda razonable, que ha existido el hecho punible investigado y que a Paul Duncan

\footnotetext{
58 "8. Lógico corolario (...) es la incorrección de la conclusión del considerando decimoctavo de la sentencia recurrida en cuanto a que la prueba producida en juicio por el acusador fiscal, atendido su carácter de referencial e indirecta, desvanece la presunción simplemente legal contenida en la Ley No 20.000, y es insuficiente para destruir la presunción de inocencia que beneficia al acusado, toda vez que al configurarse los hechos que son el supuesto de la presunción legal, no puede el Tribunal excusarse de aplicar la norma alegando que le asisten dudas razonables, como así lo afirma en el párrafo final del considerando decimoséptimo, sobre la concurrencia del dolo o elemento subjetivo del tipo penal, ya que la misma debe recaer sobre los supuestos de hechos o elementos fácticos que configuran la presunción, y no sobre los elementos subjetivos, que la misma presume a partir de la acreditación de los referidos aspectos de hecho. 9. En consecuencia, si el Tribunal da por establecido los supuestos fácticos de la figura del artículo $4^{\circ}$ de la Ley o 20.000 , como así se aprecia claramente del considerando decimocuarto, éste únicamente podía entrar a considerar la existencia o no de eventuales causales de justificación, en la medida que las mismas hubiesen sido alegadas por la defensa del acusado, y de no haberse invocado las mismas sólo podía entrar a dictar sentencia condenatoria, como consecuencia lógica de su propio razonamiento, y al no haberlo hecho incurre en el vicio de errónea infracción del derecho que ha influido sustancialmente en los dispositivo del fallo", Corte de Apelaciones de Temuco, 17 de octubre de 2007, Rol No 1.048-2007.

${ }^{59}$ En la sentencia del primer juicio se lee " $[\mathrm{Q}]$ ueda de manifiesto que la prueba producida en el juicio por el acusador fiscal, atendido su carácter de referencial e indirecta, desvanece la presunción simplemente legal contenida en la Ley No 20.000, es insuficiente para destruir la presunción de inocencia que beneficia al encartado, y en consecuencia, para dar por acreditada su participación y responsabilidad penal como autor de la figura ilícita", Tribunal de Juicio Oral en lo Penal de Temuco, 29 de agosto de 2007, RIT No 73-2007, RUC 0700006159-4.
} 
Howard Morrison Cristi le ha correspondido algún grado de participación culpable y penada por la ley" ${ }^{60}$. Hoy Morrison, según informa la prensa, prepara una millonaria acción reparadora de perjuicios en contra del Fisco de Chile.

\section{b) Los efectos de las sentencias interpretativas de rechazo en la doctrina y en la jurisprudencia comparadas}

En la teoría procesal constitucional se discuten fuertemente los efectos de estas orientaciones hermenéuticas, incluso para el mismo órgano que conoce de la gestión en que se plantea el incidente. Por la naturaleza de estas decisiones la discusión se extiende a la vieja disputa sobre si la fuerza vinculante de la sentencia reposa sobre la sola parte resolutiva (decisum) o si también ha de extenderse a la parte considerativa (ratio decidendi). En esta polémica han sido especialmente influyentes la doctrina y jurisprudencia italianas, que han puesto tempranamente énfasis en la facilidad con que los ejercicios interpretativos de los jueces constitucionales invaden los poderes del juez a $q u o^{61}$ y particularmente la función nomofiláctica de las cortes de casación ${ }^{62}$. Por esa razón, la doctrina se ha dividido al momento de reconocer un efecto general de cosa juzgada a las decisiones interpretativas de rechazo, argumentando que la única vía de interpretación auténtica de la ley es la que corresponde al legislador. Por su parte, en la práctica cotidiana los tribunales superiores no siempre han estado dispuestos a considerarse vinculados por esas decisiones e incluso han llegado a negarles la fuerza de cosa juzgada para los propios jueces a quo. En otras palabras, los propios tribunales de la gestión no estarían obligados a seguir el razonamiento de la Corte Constitucional. En este último sentido, la Corte de Casación italiana declaró en un fallo de 2004 que las llamadas "sentencias interpretativas de rechazo" no obligaban a los jueces del proceso desde el cual fue elevada la cuestión de legitimidad.

Después de lamentar la falta de comprensión de la Corte Constitucional hacia los argumentos expuestos por los jueces en sucesivos autos (u ordenanzas) de remisión sobre una misma cuestión, la Corte de Casación delimitó con mucha claridad el efecto "endoprocesales" de las sentencias interpretativas para los jueces del proceso. Por su interés, vale la pena transcribir completamente la cita:

"[S]i las decisiones interpretativas de rechazo carecen de eficacia erga omnes y no vinculan a los jueces, debe necesariamente concluirse que a la interpretación escogida

${ }^{60}$ Tribunal de Juicio Oral en lo Penal de Temuco, 9 de julio de 2008, RIT No 73-2007, RUC 0700006159-4.

${ }^{61}$ Mortati (1960), p. 925

${ }^{62}$ Pizzorusso (1981), p. 285. 
por la Corte [Constitucional] sólo puede atribuirse el valor de un precedente influyente, siempre que, obviamente, éste sea estructurado mediante argumentaciones persuasivas que induzcan a los jueces -en el ejercicio de sus funciones autónomas a compartirlo y hacerlo propio. En definitiva, no basta con que el juez de las leyes defina cierta interpretación como constitucionalmente vinculante y como la única compatible con las normas de la Constitución para que ella pueda imponerse a los jueces. Estos últimos se deben verificar autónomamente, mediante el uso de todos los instrumentos hermenéuticos de que disponen, si la norma puede realmente asumir aquel significado y alcance. Cuando las premisas hermenéuticas de la solución constitucionalmente proclamada como vinculante traspasen los límites de la interpretación literal-lógico-sistemática, los jueces tienen el deber de no atenerse a esa solución, por la decisiva razón que, en caso contrario, desaplicarían una norma vigente y ocasionaría una vulneración al principio de legalidad y sujeción a la ley" ${ }^{63}$.

Un comentarista de esta decisión sugiere que tras muchas décadas de experimentación todavía no se puede hablar de una consolidación del "rico instrumental decisorio" y que el mejor remedio para prevenir los conflictos entre las cortes no es el "enjaulamiento" de la reforma legal sino el propio control de la Corte Constitucional $^{64}$.

\section{c) Interpretación del Derecho en el proceso chileno de inaplicabilidad: el carácter vinculante de la sentencia interpretativa desestimatoria}

Las sentencias interpretativas admiten varias modalidades. En un esfuerzo simplificador, ellas pueden excluir por inconstitucional una determinada significación del enunciado $(v \cdot g r$. el precepto legal no significa W, pero puede significar X, Y o Z) o identificar el único sentido compatible con la Constitución (v. gr. el precepto legal significa Z, y por lo tanto no puede significar W, X o Y). Entre estas dos fórmulas, naturalmente la primera es más deferente con la función jurisdiccional que la segunda. Sin embargo, en la medida en que la sentencia del Tribunal es una orden para los jueces de la gestión concreta, no puede sino estimarse que en cualquiera de sus modalidades la interpretación judicial asociada al precepto legal deviene en obligatoria para los órganos jurisdiccionales de la gestión. No tienen efecto vinculante general, pero sí efecto particular.

Parte autorizada de la doctrina procesal constitucional chilena, representada por el Profesor Andrés Bordalí, sigue la doctrina europea sugiriendo que las sentencias

${ }^{63}$ Corte de Casación italiana, sentencia No 23.016/2004, 17 de mayo de 2004, considerando $7^{\circ}$ (trad. propia).

${ }^{64}$ Celoto (2009), pp. 195-196. 
interpretativas invaden los dominios de la casación del mismo modo en que la casación por infracción de la Constitución invade los dominios de la judicatura constitucional $^{65}$. Esta afirmación general, especialmente su primera parte, podría ser considerada apropiada para la realidad nacional si el actual instituto de la inaplicabilidad fuese enteramente una herramienta de control de la legislación. Sin embargo, ello no es así. En efecto, el muy peculiar diseño de la cuestión de inaplicabilidad no se corresponde con los controles incidentales generales que conducen a la expurgación de las leyes inconstitucionales del ordenamiento jurídico. No es tanto, como ha quedado dicho, un proceso de control de la legislación como uno de control de la jurisdicción. En este último sentido, como lo ha subrayado la doctrina, la inaplicabilidad tiene tanto un efecto represivo como preventivo para el ejercicio de la función jurisdiccional. Es represivo cuando el precepto ya ha sido aplicado en alguna instancia de la gestión y preventivo cuando esa aplicación se encuentra pendiente ${ }^{66}$. De ahí entonces que la metáfora explicativa de la inaplicabilidad como una "super casación" ${ }^{\text {" }} \mathrm{o}$ una "casación adivinatoria" ${ }^{68}$ describe con mucha agudeza la naturaleza recursiva de la nueva acción de inaplicabilidad. Esta naturaleza ciertamente puede resultar a partir de un diseño institucional autopoiético, improvisado y hasta errado ${ }^{69}$ curiosamente híbrida, pero lo cierto es que ella tiene una importante incidencia para el diseño y ejercicio de la jurisdicción. Esta transformación lleva, como proceso natural, a la reformulación de la nomofilaxis como fin -ya no exclusivo de la casación.

Vistas así las cosas, una vez abierto el proceso de inaplicabilidad la interpretación del precepto legal cuestionado y, por lo tanto, la determinación de la regla de derecho aplicable, no se define por un solo órgano jurisdiccional ni menos por una sola estructura judicial. Por el contrario, ese proceso se fragmenta y construye jurisdiccionalmente entre órganos y órdenes jurisdiccionales distintos. En este proceso constitucional-dialéctico que es propio de la gestión judicial, necesariamente unos resultan subordinados al parecer de los otros. Naturalmente, tratándose de órganos que pertenecen a una misma estructura orgánica, la sujeción del inferior a los dictados del superior no sólo es fácil de comprender sino que también es fácil de

\footnotetext{
${ }^{65}$ Bordalí (2009), pp. 47-71.

66 Pfeffer (2011), p. 209.

${ }^{67}$ Vega y ZúNíga (2006), p. 155.

${ }^{68}$ Aldunate (2007), p. 42.

${ }^{69}$ En cuanto a los posibles errores importantes de diseño, véase Couso y Coddou (2010), p. 420. Para el primero de estos autores, parte de los errores y dificultades conceptuales no sólo se advierten en la jurisprudencia del Tribunal sino también en la reforma a la LOCTC, vid. Couso (2010), pp. 46-50.
} 
aceptar. Por el contrario, cuando se trata de tribunales que no están orgánicamente relacionados y cuyo vínculo sólo resulta de un proceso, la obediencia se hace más difícil, pero no por ello se torna en inexistente. Por eso también conviene recordar lo que es propio de las relaciones entre los tribunales nacionales y los internacionales, que no es otra cosa que los tribunales nacionales deben cumplir de buena fe con las decisiones de los tribunales internacionales.

\section{d) Dificultades de las sentencias interpretativas que justifican la auto restricción del Tribunal Constitucional}

Como es lógico, el efecto vinculante de las sentencias con declaración de interpretación es relativo, esto es, se circunscribe a la causa en que se dicta la sentencia de interpretación. Este efecto vinculante particular de la sentencia interpretativa de inaplicabilidad descarta la naturaleza legislativa de ese procedimiento y, junto con ello, las críticas sobre la supuesta usurpación de las atribuciones que corresponden al legislador como intérprete auténtico de las leyes. Se trata, en otras palabras, de una resolución dotada de Rechtskraft y no de Gesetzkraft. Con todo, la obligatoriedad de esta forma de interpretación judicial no implica desconocer sus problemas. Por una parte, el tribunal de la gestión estará usualmente obligado a identificar el sentido de la decisión en sus fundamentos. En otras palabras, el modo de atribuir significado al precepto legal cuestionado y salvado condicionalmente en su constitucionalidad estará explicado en la ratio decidendi de la sentencia. Esto produce un efecto llamado en otras latitudes "reenvío a la motivación" "qu que no siempre facilita la comprensión de las sentencias y que en Chile se produce incluso con sentencias no interpretativas ${ }^{71}$.

Un segundo problema, más agudo, radica en la generalidad del discurso interpretativo de conformidad, que hace que muchas veces lo que se dice para un caso respecto de la significación de un precepto legal valga también para los demás. A partir de esta generalidad se esperaría que la doctrina del Tribunal corrigiera y modelara -a partir de la auctoritas y no de la potestas el modo en que los tribunales interpretan la ley. Sin embargo, ello no siempre es así, advirtiéndose un escaso efecto práctico de estas interpretaciones. Así, la experiencia demuestra que la sentencia estimatoria es más eficaz que una interpretativa de rechazo, como lo han reconocido hidalgamente los ministros Venegas, Bertelsen, Fernández Baeza y Aróstica en una de las varias sentencias relativas a la figura procesal penal de la

\footnotetext{
70 Pizzorusso (1981), p. 285.

${ }^{71}$ Véase por ejemplo la STC (estimatoria) Rol No 1.615, 20 de enero de 2011. En este fallo el objeto de la decisión no se entiende sino con relación a su fundamento $21^{\circ}$.
} 
formalización de la investigación. Esta suerte de nula eficacia de la doctrina interpretativa sostenida en fallos como la STC Rol No 1.380 o la Rol No 1.337, ambas de 2009, es reconocida en la disidencia de la STC 1484 de 2010:

“ $4^{\circ}$. Que, en efecto, tanto en la sentencia Rol N 1.337 , considerandos $7^{\circ}$ y $8^{\circ}$, como en la sentencia Rol $N^{\circ} 1.380$, considerandos $10^{\circ}$ a $13^{\circ}, 17^{\circ}$ y $18^{\circ}$, esta Magistratura expuso las razones por las cuales, en dichas causas, el Tribunal estuvo por no declarar inaplicable el artículo 186 del Código Procesal Penal, al estimar que el precepto impugnado permite al juez de garantía fijar un plazo para que el fiscal formalice la investigación, incluso cuando lo solicite el ofendido y querellante;

$5^{\circ}$. Que, sin embargo, el Tribunal no conoce causas que demuestren que el Ministerio Público o los jueces de garantía hayan seguido en algún caso la interpretación que el Tribunal Constitucional tuvo en cuenta anteriormente para salvar la constitucionalidad del artículo 186 del Código Procesal Penal. Muestra inequívoca, por lo demás, de la posición del Ministerio Público sobre la materia, es la postura que ha tenido en la presente causa, en que ha reiterado que el ofendido por el delito y querellante, no puede obtener del juez de garantía la orden de que el Fiscal formalice la investigación”72.

Frente a estas circunstancias, los disidentes fueron de la opinión de acoger la acción de inaplicabilidad.

Un par de meses antes del voto recién transcrito, los mismos disidentes habían adelantado el espíritu de la crítica al voto de mayoría, señalado que "la interpretación y aplicación de los preceptos legales ha de efectuarse de tal forma que todos los principios y normas de la Carta Fundamental sean efectivamente cumplidos y produzcan concretos efectos prácticos, debiendo desecharse, por consiguiente, cualquiera solución que traiga como resultado el mero respeto nominal o la ineficacia real de los mismos"73.

Por las razones anotadas la técnica de las sentencias interpretativas es, en general, desaconsejada.

\section{e. La errónea prospección (o errada "adivinación") de la aplicación del Derecho ¿produce cosa juzgada?}

Como se dijo más arriba, el juicio de inaplicabilidad supone pronunciarse sobre los efectos que genera la aplicación de un precepto legal a una gestión judicial pendiente. Los efectos resultan de una aplicación pretérita o, particularmente cuando

\footnotetext{
${ }^{72}$ STC Rol No 1.484, 5 de octubre de 2010, voto disidente de los ministros Venegas, Bertelsen, Fernández Baeza y Aróstica, $4^{\circ}$ y $5^{\circ}$, cursivas añadidas.

${ }^{73}$ STC Rol No 1.542, 31 de agosto de 2010, voto disidente de los ministros Venegas, Bertelsen, Fernández Baeza y Aróstica, $2^{\circ}$.
} 
la inaplicabilidad se solicita en las fases iniciales de un proceso, simplemente potencial. A este último corresponde el adjetivo de "adivinatorio" con que el Profesor Eduardo Aldunate ha calificado la naturaleza recursiva de la inaplicabilidad. La profundidad del examen relativo a esta posibilidad ha sido tratada en la jurisprudencia $^{74}$ y ha oscilado entre la exigencia de la "sola posibilidad"75 y la exigencia de una "posibilidad real" mayor a la simplemente "hipotética y teórica"76. En este último extremo se encuentra un caso que bien permite describir la problemática anticipada en el epígrafe. Se trata del caso Sánchez Eyquem, donde el requirente querellante particular en una causa penal pretendía la inaplicabilidad de aquellos preceptos del Código Procesal Penal que otorgan facultades al Ministerio Público para formalizar discrecionalmente y para solicitar, previo acuerdo del imputado, la suspensión condicional del procedimiento. A juicio del requirente, los preceptos legales impugnados dejaban al ofendido en una situación de desprotección que vulneraría la Constitución.

En Sánchez Eyquem, el Tribunal estimó que "los preceptos impugnados no tienen una posibilidad real de ser aplicados y ser decisivos, sino tan sólo una posibilidad hipotética y teórica, y es menester diferenciar estas situaciones, por cuanto la segunda de ellas no amerita un pronunciamiento de este sentenciador, desde el momento en que no ha sido llamado a emitir pronunciamientos de inaplicabilidad de eficacia hipotética" ${ }^{7}$. Más adelante añadió "que el requerimiento de autos tampoco podría ser objeto de una sentencia estimatoria, desde el momento en que, al apoyarse en elucubraciones sobre el curso futuro del proceso penal pendiente prescindiendo de circunstancias concretas y reales, envuelve más bien una pretensión de inconstitucionalidad en abstracto respecto de institutos procesales como lo son la formalización de la investigación y las salidas alternativas" ${ }^{38}$.

Más allá de la problemática de fondo, el caso se hacía interesante en el supuesto en que el procedimiento efectivamente fuera suspendido, como aparentemente sucedió $^{79}$. La pregunta que surge entonces es si la decisión desestimatoria produce cosa juzgada. Para responder a esta pregunta es posible extender el mismo principio que se explicó con ocasión de la identidad de gestión en el caso de la

\footnotetext{
${ }^{74}$ Filloy y Soto (2011), pp. 238 y ss.

${ }^{75}$ Véanse las SSTC Rol No 1.405, 3 de agosto de 2010, con referencia a la jurisprudencia anterior; y Rol No $1.295,6$ de octubre de 2009 .

${ }^{76}$ Véase el fallo dividido STC Rol No 1.145, 21 de enero de 2010, considerando $36^{\circ}$.

${ }^{77}$ STC Rol No $1.445,21$ de enero de 2010, considerando $36^{\circ}$.

${ }^{78}$ STC Rol No 1.445, 21 de enero de 2010, considerando $37^{\circ}$.

${ }^{79}$ Cuarto Juzgado de Garantía de Santiago, RIT No 6118-2009, RUC No 0900447112-9.
} 
inadmisibilidad: si la sentencia desestimatoria se dicta de acuerdo con un estado determinado de la gestión y ese estado puede variar sustancialmente en el tiempo, es lógico que el efecto de cosa juzgada de la sentencia desestimatoria se limite rebuc sic stantibus. En otras palabras si el fallo solamente se sustenta en una prospección de la incidencia del precepto legal en la gestión y luego se demuestra que esa prospección fue equivocada, la cosa juzgada de la sentencia sería una de tipo simplemente formal y no material.

\section{LOS EFECTOS DE LA SENTENCIA ESTIMATORIA DE INAPLICABILIDAD: HACIA EL} EFECTO ÚTIL DE LA SENTENCIA DE INAPLICABILIDAD

\section{A. Obligatoriedad de la sentencia a partir de una comprensión sistemática de la} jurisdicción judicial (arts. 76 y 82 CPR) y la jurisdicción constitucional (art. 96 CPR)

Tanto la sentencia estimatoria parcial ${ }^{80}$ como la estimatoria total generan en el tribunal de la gestión la obligación de no aplicar el precepto legal a la solución del caso. Este es el efecto negativo o inhibitorio que en palabras del Tribunal "se traduce en que, declarado por esta Magistratura que un precepto es inaplicable en la gestión respectiva, queda prohibido al tribunal ordinario o especial que conoce de ella aplicarlo" ${ }^{\text {} 1 . ~ P a r a ~ e l ~ c a s o ~ c o n c r e t o, ~ e s t o ~ s i g n i f i c a ~ q u e ~ l a ~ s e n t e n c i a ~ d e ~}$ inaplicabilidad retira del ordenamiento jurídico el precepto legal que vinculaba positivamente al juez hasta el fallo de inaplicabilidad. Si la sentencia interpretativa desestimatoria retira del universo hermenéutico algún sentido de la norma, el fallo estimatorio es más radical y expulsa el enunciado normativo de la justificación de la sentencia. En definitiva, la inaplicabilidad judicialmente declarada opera como una suerte de dispensa de Tribunal a tribunal, que aunque no libera al juez de la gestión de su inexcusable deber de fallar, lo exime de la obligación de aplicar el precepto legal cuestionado si se han dado todos los supuestos hipotéticos para que la norma sea aplicable al caso. Esta dispensa particular genera un pseudovacío legal o una laguna impropia, que es inmediatamente llenada por las reglas comunes y los principios generales que corresponde aplicar en virtud del principio de inexcusabilidad.

La noción de "vacío legal" que aquí se utiliza proviene de la propia doctrina del Tribunal Constitucional, que ha recurrido a esta figura de la teoría del derecho

${ }^{80}$ Como ejemplos de sentencias parcialmente estimatorias véanse, a título ejemplar y con diversos matices, las SSTC roles Nos. 736, 29 de noviembre de 2007, 806, 11 de diciembre de 2007, 944, 13 de mayo de 2008, 1138, de septiembre de 2008, 1140, 14 de enero de 2009, 1234, 7 de julio de 2009, y 1580, 27 de enero de 2011.

${ }^{81}$ STC Rol No 473, 8 de mayo de 2007, considerando $9^{\circ}$. 
para explicar el efecto que genera la inaplicabilidad, particularmente cuando de lo que se trata es de justificar la improcedencia de la misma. Así, decisiones de inadmisibilidad han considerado infundado el reclamo que, de acogerse, dejaría al requirente en una situación más perjudicial ${ }^{82}$ o sentencias desestimatorias han sostenido el rechazo porque que la sentencia de acogimiento produciría "un vacío legal que dejaría sin cumplirse un expreso mandato constitucional"83 o que dejaría sin sustento la propia construcción del requirente ${ }^{84}$

La sentencia de inaplicabilidad no implica un pronunciamiento de fondo sobre los hechos. El carácter concreto de esta competencia constitucional sólo permite al Tribunal conocer y ponderar los hechos del proceso, según como están establecidos en él, para evaluar la posible infracción a la Constitución que se derive de la aplicación del precepto cuestionado. La aplicación final del Derecho a esos hechos es una competencia privativa del juez de la instancia y, por lo tanto, un límite a la competencia del Tribunal Constitucional. Esta limitación ha sido fundada desde los primeros años de vigencia de la nueva inaplicabilidad en el principio de deferencia razonada ${ }^{85}$, que obliga al Tribunal a respetar las competencias de los jueces del fondo y a pronunciarse sólo limitadamente -esto es, en la estricta medida del juicio de inaplicabilidad ${ }^{86}$ respecto del modo en que se ha interpretado y aplicado el precepto legal. En fecha reciente el Tribunal ha incluido este obvio principio en la parte resolutiva de una sentencia que declaró inaplicable el art. 126 bis del Código del Trabajo:

“2. Corresponderá al juez requirente determinar la norma aplicable al caso concreto sobre el que incide esta sentencia de inaplicabilidad, toda vez que esta decisión no prejuzga acerca de la norma legal que debe aplicarse en reemplazo del precepto cuestionado, cuestión que es de competencia del Tribunal a quo y no de esta Magistratura" ${ }^{37}$.

Como la sentencia de inaplicabilidad no juzga el fondo sino sólo los argumentos legales para decidirlo, el principio entonces es el de la libertad del juez de la instancia para sentenciar la gestión de acuerdo con aquellas otras fuentes que no hayan sido afectadas por la sentencia de inaplicabilidad. De allí que pueda afirmarse concordando las competencias constitucionales de los tribunales de justicia y el

\footnotetext{
${ }^{82}$ Así por ejemplo, STC Rol No 1.913, 9 de marzo de 2011, considerando $7^{\circ}$.

${ }^{83}$ STC Rol No 996, 4 de diciembre de 2007, considerando $5^{\circ}$.

${ }^{84}$ STC Rol, No 986, 30 de enero de 2008, considerando $13^{\circ}$.

${ }^{85}$ Véanse, entre otras, STC roles No 498, 2 de mayo de 2006; No 503,19 de julio de 2006; No 551, 8 de agosto de 2006; No 522, 16 de agosto de 2006; 790, 11 de diciembre de 2007.

${ }^{86}$ Véase el voto del Ministro Correa en las STC Rol No 810, 24 de enero de 2008, apdo. $9^{\circ}$.

${ }^{87}$ STC Rol No 1852, 26 de julio de 2011, parte resolutiva.
} 
Tribunal Constitucional que tanto las potestades de resolver una causa (art. 76 $\mathrm{CPR}$ ), como las de supervigilar disciplinariamente el ejercicio de la jurisdicción (art. $82 \mathrm{CPR}$ ), son necesariamente limitadas por la potestad de definir con efectos vinculantes cuál es la ley no aplicable a la gestión (art. 93.6 CPR). Esta necesaria concordancia de atribuciones no sólo facilita la comprensión del modo en que el fallo de inaplicabilidad incide en cualquier gestión judicial, sino que también obliga a considerar con recíproca lealtad constitucional el ámbito de atribuciones de cada orden jurisdiccional. Esta recíproca lealtad, aunque no purga, ciertamente acota la amenaza latente de una guerra fra le due corti.

El proceso ideal de cumplimiento de la sentencia de inaplicabilidad es aquel donde el tribunal de la gestión, en los distintos grados del proceso, no sólo registra la sentencia de inaplicabilidad a través de la fórmula sacramental "a fojas ... rola la sentencia de inaplicabilidad de fecha..." sino que descifra su significado en el proceso y, al momento de resolver el asunto sometido a su conocimiento, justifica la inaplicación legal con el mandato judicial del Tribunal Constitucional. Así por ejemplo, en Arroyo Aguirre la Corte de Apelaciones de Concepción relata del siguiente modo el efecto que corresponde a la STC de inaplicabilidad Rol No 767, de 30 de octubre de 2007:

"Que la sentencia referida en el considerando anterior y que rola en copia autorizada de fojas 153 a fojas 173, resolvió acoger el requerimiento de inaplicabilidad por inconstitucionalidad planteado por el abogado Francisco Rojo Olavarría, respecto del artículo 1 de la ley 18.865, en la presente causa laboral, lo que según se indica en el considerando sexto de la sentencia del Tribunal Constitucional, implica la prohibición del tribunal que conoce de la causa, de fundar su decisión en el mismo, lo que implica también, como se concluye asimismo en la consideración duodécima del referido fallo, que debe entrar a determinarse si concurren en el caso en cuestión los elementos de la relación laboral"s8.

La lectura del fallo es bastante precisa: hay una sentencia del Tribunal Constitucional dictada para esa causa, ese fallo ordena no aplicar un precepto legal y, como consecuencia de ello, se abre para el demandante la posibilidad de reclamar la existencia de una relación laboral que el precepto legal inaplicable obligaba a desconocer.

En Balmaceda Jarufe, el primero de una saga de casos conocidos como "Fondo de Crédito Universitario", la Corte de Valparaíso resume en un motivo del fallo de protección la STC Rol No 808, de 12 de agosto de 2008, y concluye que:

${ }^{88}$ Corte de Apelaciones de Concepción, 28 de diciembre de 2007, Rol No 3208-2006, considerando $12^{\circ}$. 
"[T] anto el acto de la Pontificia Universidad Católica de Valparaíso cuanto el de la Tesorería General de la República se realizó conforme a una norma que ha sido declarada inaplicable, para este caso, por inconstitucionalidad vulnerando derechos de aquellos que protege la Constitución Política de la República en el artículo 20 de la misma al retenerse por Tesorería de la devolución anual de impuestos que correspondía al recurrente, para pagar un crédito del Fondo Solidario de Crédito Universitario con la sola información que el Administrador del mismo proporcionó a dicho Servicio" $"$.

Según la Corte porteña con la declaración posterior de inaplicabilidad devienen en ilegales los actos pretéritos de ejecución (privados y administrativos en este caso) de la ley declarada inaplicable.

De modo similar a los casos recién reseñados, la segunda Sala de la Corte Suprema, fallando un recurso de casación en el fondo, acata la STC Rol No 1419, de 9 de noviembre de 2010, relativa al art. 2331 del Código Civil:

"Que, en el capítulo dedicado al quebrantamiento del artículo 2.331 del Código Civil, consta en autos a fojas 1737 y siguientes del Tomo IV, copia autorizada de la sentencia del Tribunal Constitucional de nueve de noviembre de dos mil diez, originada con motivo del requerimiento del Abogado Fernando Molina Vallejo, querellante en esta causa, respecto de la inaplicabilidad por inconstitucionalidad de la norma citada a este proceso penal, el que fue acogido por vulnerar lo dispuesto en el artículo $19 \mathrm{~N}^{\circ} 2$ de la Constitución Política de la República, referido a la igualdad ante la ley, de forma tal que la alegación de improcedencia del daño moral en la especie carece de todo sustento" 90 .

En este último caso la sentencia de casación ratifica la argumentación de la Corte de Santiago, que previo a la declaración de inaplicabilidad ya había confirmado una sentencia civil condenatoria contra la letra expresa de la señalada norma del Código Civil. En sentido similar, y referida a la misma norma civil, puede verse la sentencia de primera instancia del juicio Maira c. Fisco que cumple textualmente con la STC Rol No 1741, de 15 de marzo de 2011:

"Que, por lo tanto, atendido el principio de la reparación integral del daño, en relación a lo decidido por el Excmo. Tribunal Constitucional, en cuanto a la inaplicabilidad para el presente caso del artículo 2331 del Código Civil, como también, la naturaleza del derecho afectado, su prestigio como docente universitario y las consecuencias personales y laborales que produce el hecho ilícito en la vida de la víctima, (...) se

\footnotetext{
${ }^{89}$ Corte de Apelaciones de Valparaíso, 8 de septiembre de 2008, Rol o 296-07, considerando $6^{\circ}$.

${ }^{90}$ Corte Suprema, 30 de junio de 2011, Rol No 7914-2008, considerando $14^{\circ}$, cursivas añadidas.
} 
concluye que se otorgará a título de perjuicios, por daño moral, la suma de (...), en razón del mérito de la prueba rendida" ${ }^{\prime 1}$.

\section{B. El presunto vacio legal no libera a los jueces de la obligación de dictar sentencia: los primeros desvios de los mandatos de inaplicabilidad}

La declaración de inaplicabilidad, si bien margina del caso al precepto declarado inaplicable, no inhabilita a los jueces de la gestión para resolver el asunto conforme al principio de inexcusabilidad y al mérito del proceso. Aunque no es competencia del Tribunal dirigir el curso posterior del proceso más allá de lo que representa resolver la no aplicación del precepto legal, es posible encontrar algunas sutiles indicaciones nunca obligatorias sobre el curso futuro de la gestión. Así por ejemplo, en uno de los primeros fallos relativos al antiguo art. $116 \mathrm{del} \mathrm{C}$. Tributario, el Tribunal se elucubra el posible destino del proceso tras la declaración de inaplicabilidad:

“[S]i se determina que el aludido precepto legal contraviene la Constitución, resultará que la sentencia dictada por el Juez Tributario de la XIII Dirección Regional Metropolitana del Servicio de Impuestos Internos, el 23 de mayo de 2003, fue dictada, por quien no tenía la calidad de juez adoleciendo, entonces, de un vicio que vulnera tanto el inciso $1^{\circ}$ como el inciso $2^{\circ}$ del artículo $7^{\circ}$ del Código Político, lo que no puede resultar indiferente a los jueces del fondo" 92 .

Como es de público conocimiento, el pronóstico del Tribunal Constitucional fue el acertado, dado que la gran mayoría de los procesos afectados por la declaración de inaplicabilidad del art. 166, e incluso los teóricamente no comprendidos por la posterior declaración de inconstitucionalidad, terminaron por ser anulados.

Con todo, el llenado del supuesto vacío que genera la declaración de inaplicabilidad no fue tan sencillo en los casos relativos al desafuero parlamentario por delitos de acción privada. En uno de los primeros fallos de inaplicabilidad, el caso Girardi, el Tribunal Constitucional señaló que:

"[A] esta Magistratura le corresponde exclusivamente decidir sobre la inaplicabilidad de un precepto legal en un caso determinado, por lo que resulta improcedente, en

${ }_{91} 29^{\circ}$ Juzgado Civil de Santiago, 21 de marzo de 2011, Rol № C-28538-2009, considerando $31^{\circ}$. A la fecha de cierre de este trabajo la causa se encontraba apelada ante la Corte de Apelaciones de Santiago, Rol No 2625-2011.

${ }^{92}$ STC Rol No 472, 30 de agosto de 2006, considerando $24^{\circ}$. 
la especie, discurrir una solución que resuelva algún posible vacío legal sobre la base de la aplicación inmediata de la Constitución, reglas comunes a todo procedimiento y principios generales del derecho que puedan operar en virtud del principio de la inexcusabilidad"'3.

El Tribunal parecía estar sugiriendo que la desaparición particular de la norma declarada inaplicable no afectaba la vigencia de los mandatos jurídicos que nacen de la Constitución, de las leyes y de los principios generales del Derecho. Esta sugerencia no fue sin embargo oída por la Corte de Apelaciones de Santiago que, con un numeroso voto en contra, resolvió no aplicar todo el proceso constitucional de desafuero, dejando sin aplicación la propia Constitución, y archivar los antecedentes:

" $3^{\circ}$ Que de estos antecedentes aparece que por sentencia de ocho de agosto pasado, el Tribunal Constitucional acogió la cuestión de inaplicabilidad deducida por el señalado senador, declarando en consecuencia que es inaplicable en el proceso sobre desafuero seguido ante la Corte de Apelaciones de Santiago, ingreso de corte Rol $\mathrm{N}^{\circ}$ 2.257-2.006, el precepto contenido en el inciso tercero del artículo 416 del Código Procesal Penal que señala: 'Si se tratare de un delito de acción privada, el querellante deberá ocurrir ante la Corte de Apelaciones solicitando igual declaración, (de formación de causa) antes de que se admitiere a tramitación su querella por el juez de garantía'. Que teniendo en consideración lo antes relacionado, y especialmente presente lo resuelto por el Tribunal Constitucional, esta Corte no emitirá pronunciamiento acerca de la petición de desafuero formulada en la presentación de fojas 47 y siguientes $y$ ordenará su archivo"94.

Similar desvío padeció la sentencia estimatoria de inaplicabilidad del caso Longueira $^{95}$, dictada unos meses después de Girardi. En Longueira la Corte de Apelaciones de Santiago extrajo una consecuencia todavía más extraviada de la jurisprudencia constitucional, cual era la incompetencia sobrevenida del tribunal de alzada:

"El mérito de los antecedentes, lo expuesto en la presentación que se resuelve por esta vía, y teniendo especialmente en consideración que el pronunciamiento del Tribunal Constitucional emitido por sentencia de nueve de noviembre pasado, recaído en los autos Rol No 529-2.006 de ese tribunal, priva a esta Corte de competencia para conocer

\footnotetext{
${ }^{93}$ STC Rol No 478, 8 de agosto de 2006, considerando $24^{\circ}$.

${ }^{94}$ Corte de Apelaciones de Santiago, 23 de agosto de 2005, Rol No 2257-2006, 23 de agosto de 2006, considerando $3^{\circ}$.

${ }^{95}$ STC Rol No 529, 9 de noviembre de 2006.
} 
de la solicitud efectuada en la presentación de fojas 2, de manera que importa en el presente caso el término de este procedimiento de desafuero, toda vez que por medio de dicha resolución declaró inaplicable por inconstitucionalidad el inciso tercero del artículo 416 del Código Procesal Penal, normativa que establece la oportunidad procesal en que el querellante debe ocurrir ante la Corte de Apelaciones respectiva para el objeto de solicitar la declaración de desafuero de un parlamentario en el caso de los delitos de acción privada, se acoge el recurso de reposición deducido por el abogado Cristian Letelier Aguilar, en representación del H. Senador don Pablo Longueira Montes, y en consecuencia se declara que esta Corte no emitirá pronunciamiento acerca de la petición de desafuero formulada en la presentación de fojas 2 y siguientes, y se ordenará su archivo" 96 .

Como se sabe, el peculiar destino que tuvo el fallo estimatorio de inaplicabilidad en los casos Girardi y Longueira hizo que posteriormente el Tribunal precisara su criterio estimando que la mejor alternativa procesal era el acogimiento limitado de la cuestión de inaplicabilidad sólo en cuanto el tribunal de alzada "no podrá aplicar lo dispuesto en el inciso tercero del artículo 416 del Código Procesal Penal en lo que éste le pueda impedir decretar prueba en caso de que, a su juicio, ella resulte necesaria. Déjese sin efecto la suspensión decretada en autos"97. Este último fallo fue precedido de una importante confesión del Tribunal Constitucional sobre la errada interpretación de que habían sido objeto sus fallos de inaplicabilidad ${ }^{98}$.

\section{La inaplicabilidad del fallo de inaplicabilidad: los caminos del proceso son inescrutables}

Más arriba se explicaba cómo el vencedor de la inaplicabilidad podía ser derrotado en la gestión principal y viceversa. La razón de ello es que no pocas veces los destinos del proceso sólo pueden ser adelantados mediante una prognosis

\footnotetext{
${ }^{96}$ Corte de Apelaciones de Santiago, 11 de diciembre de 2006, Rol No 7.203-2006, considerando único.

${ }^{97}$ STC Rol No 806, 11 de diciembre de 2007, parte resolutiva.

${ }^{98}$ Véase la STC Rol No 558 (590), 5 de junio de 2007, considerandos $21^{\circ}$ y ss. En este fallo se lee: "Que la eventual derogación del precepto cuestionado origina un vacío o laguna legal, ante el cual se impondría la fuerza normativa y eficacia directa de la norma del artículo 61, inciso segundo, de la Constitución, según la cual ningún diputado o senador puede ser acusado o privado de su libertad si el Tribunal de Alzada correspondiente no autoriza previamente la acusación declarando haber lugar a la formación de causa. Sin embargo, según se ha entendido por tribunales de alzada (sentencias de la Corte de Apelaciones de Santiago, desafueros Roles No 2.257-2006 y No 7.714-2006), la inaplicación del artículo 416, inciso tercero, del Código Procesal Penal, les inhibe proseguir la tramitación de desafueros, lo que ha provocado el decaimiento (archivo) de las acciones ventiladas. Se ha decidido en esos casos que 'teniendo especialmente presente lo resuelto por el Tribunal Constitucional, esta Corte no emitirá pronunciamiento acerca de la petición de desafuero formulada en la presentación de fojas 1 y siguientes y ordenará su archivo'”, considerando $21^{\circ}$.
} 
muy superficial de su curso. Requirente y requerido pueden llegar a un acuerdo (como sucedió en alguna de las más relevantes causas del art. 2331 del Código Civil), el proceso puede ser abandonado y no registrar gestión útil alguna tras la sentencia de inaplicabilidad, o bien en lo que importa para los efectos de la presente investigación es posible que el juicio de término se acerque más a las advertencias de los disidentes del fallo de inaplicabilidad que al voto de mayoría o que simplemente la sentencia de término se desvíe de la "teoría del caso" ensayada por el Tribunal Constitucional. En otras palabras, los destinos del proceso pueden hacer real lo que parece una paradoja, esto es, que el fallo de inaplicabilidad sea también inaplicable.

Así por ejemplo, en Fernández Bitterlich, uno de los casos pioneros de la saga Isapres, la tercera Sala de la Corte Suprema siguió un camino distinto al advertido por el voto de mayoría y recibió la tesis que el voto disidente (Ministro Navarro) acertó en formular:

"[L]a norma declarada inaplicable por inconstitucional", carece de imperio respecto del contrato que vincula al actor con la Isapre Colmena Golden Cross. En efecto, el legislador expresamente exceptuó de la regulación contenida en el artículo 199 a aquellos contratos anteriores que habían incorporado las aludidas tablas de factores de sexo y edad, prescribiendo como ya se consignó que tratándose de dichos contratos operará lo acordado al momento de su celebración. En consecuencia, y como lo señalara el Ministro del Tribunal Constitucional, don Enrique Navarro Beltrán, en su disidencia, el precepto en cuestión no resulta aplicable para la resolución del asunto sometido al conocimiento de esta Corte, pues no forma parte del estatuto jurídico que rige la relación contractual existente entre el reclamante y la Isapre mencionada" ${ }^{100}$. De acuerdo con esta tesis no hacía falta la declaración de inaplicabilidad si la norma era, ratione tempore, impertinente al caso.

En un caso más reciente, los tribunales volvieron a fallar junto al voto disidente de la sentencia constitucional. A propósito de otra de las inaplicabilidades declaradas sobre el art. 2331 del Código Civil ${ }^{101}$, la Corte de Apelaciones de Santiago falló la gestión judicial confirmando la sentencia que no había aplicado el art. 2331 por tratarse de una situación no regida por él. El fallo confirma la sentencia de primera instancia y escuetamente indica que "la documentación agregada a los autos en esta instancia y las alegaciones formuladas en estrados, por los abogados

${ }^{99}$ STC Rol No 1.287, 8 de septiembre de 2009.

${ }^{100}$ Corte Suprema, 26 de octubre de 2009, Rol No 7.779-2008, considerando $11^{\circ}$.

${ }^{101}$ STC Rol No 1.463, 23 de septiembre de 2009. 
de las partes, no alteran los fundamentos del fallo de primer grado ni lo que viene decidido" 102 . Aunque el fallo no lo dice, la sentencia confirma las advertencias que la Ministra Peña y los Ministros Navarro y Fernández Fredes habían adelantado en su voto de minoría.

En el caso Camiroaga la ratio decidendi para resolver la no aplicación del art. 2331 del Código Civil no es la sentencia estimatoria de inaplicabilidad ${ }^{103}$, sino la inexistencia de la injuria que sirve de premisa para la aplicación de dicho precepto legal ${ }^{104}$. El razonamiento es simple: si no hay injuria desaparece la hipótesis de hecho de una norma que, aún sin fallo de inaplicabilidad, no podía ser aplicada en la gestión pendiente.

Por último, en otro de los casos vinculados a las inaplicabilidades acogidas del Fondo de Crédito Universitario ${ }^{105}$, la Corte de Santiago resolvió la "falta de incidencia" del fallo de inaplicabilidad por faltar la prueba que permitía configurar la hipótesis de hecho de la norma declarada inaplicable:

" $5^{\circ}[\mathrm{D}] \mathrm{el}$ análisis de los antecedentes recabados, aparece que no puede prosperar el recurso en cuanto se dirige en contra del Administrador General del Fondo Solidario de Crédito Universitario de la Universidad de Chile, precisamente porque no se ha proporcionado ningún elemento de juicio que permita concluir que dicho organismo solicitó a la Tesorería General de la República la retención de la devolución de impuestos correspondiente a la declaración de impuesto a la renta año 2009 del señor Espinosa Rojas. Por lo tanto, no tiene incidencia en el presente recurso lo decidido por el Tribunal Constitucional en la acción de inaplicabilidad por inconstitucionalidad ya referida, en la medida que la Tesorería General de la República al obrar de la manera de que da cuenta este expediente no dio aplicación a lo que dispone el artículo $1^{\circ}$ de la Ley $\mathrm{N}^{\circ} 19.989^{\prime 106}$.

Estas formas de inaplicabilidad de la sentencia de inaplicabilidad no son patológicas. Ellas se explican, por el contrario, en las limitaciones propias del juicio de inaplicabilidad: el proceso de inaplicabilidad no tiene por fin resolver el conflicto de fondo sino sólo dirigir -imperativamente según se ha visto la motivación de la decisión final. Las formas de inaplicación de la sentencia constitucional que

\footnotetext{
${ }^{102}$ Corte de Apelaciones de Santiago, 18 de octubre de 2011, Rol No 2.517-2008.

103 STC Rol No 1.679, 15 de marzo de 2011.

${ }^{104}$ Corte de Apelaciones de Santiago, 18 de octubre de 2011, Rol No 2.517-2008. A la fecha se encuentra pendiente un recurso de casación en el fondo contra este último fallo.

${ }^{105}$ Véase la STC Rol No 1.449, 9 de diciembre de 2010 (acogida).

${ }^{106}$ Corte de Apelaciones de Santiago, 25 de abril de 2011, Rol No 8063-2009, considerando $5^{\circ}$.
} 
importan un desvío de lo dispuesto por el Tribunal Constitucional se presentan, como se explicaba más arriba, a propósito de la equívoca comprensión del proceso de inaplicabilidad, fenómeno sobre el que se volverá a continuación.

\section{La inaplicabilidad del fallo de inaplicabilidad: se obedece pero no se cumple. \\ Sobre la correcta interpretación de la sentencia y del proceso de inaplicabilidad}

Los casos Girardi y Longueira, evidencian que una de las dificultades que pueden sobrevenir al cumplimiento de la sentencia constitucional es la de su correcta inteligencia. El camino que se ha sugerido hasta aquí para facilitar este proceso es el de la integración entre el estatuto propio de la jurisdicción ordinaria (arts. 76 y 82 CPR) y las competencias constitucionales del Tribunal de la inaplicabilidad (art. 93.6 CPR), todo ello contextualizado en un marco de deferencia y lealtad constitucional recíproca. Esta deferencia y lealtad exigen una adecuada comprensión, de parte de los tribunales de la gestión, acerca de lo que es y de lo que no es el proceso de inaplicabilidad. En este último sentido, una errada concepción del proceso y del sentido del cumplimiento de una sentencia constitucional -tanto en lo que estima como en lo que desestima puede frustrar la eficacia de la función de garantía constitucional encomendada al Tribunal por la vía de la competencia de inaplicabilidad.

En este contexto, los obiter dicta de la Corte de Apelaciones de Santiago en el mediático caso del matrimonio homosexual ${ }^{107}$ demuestran que el proceso de asimilación de la inaplicabilidad, por parte de los tribunales ordinarios de justicia, se encuentra todavía inacabado. Entender que es posible activar la competencia del No 6 del art. 93 sin requerir oficialmente de inaplicabilidad, por la simple vía de una "medida para mejor resolver", o afirmar que "las opiniones variopintas [de la sentencia constitucional] sobre el tema de fondo" hacen que el propósito de la "medida para mejor resolver" "se encuentra indirectamente cumplido" ${ }^{108}$, dificulta la adecuada sintonía entre las competencias que corresponden al Poder Judicial y las que posee el Tribunal Constitucional.

Una segunda anomalía de concepción se advierte en las sentencias que, a partir de la negativa de un supuesto efecto retroactivo de la decisión de inaplicabilidad, desconocen el sentido mismo de la inaplicabilidad. Mediante esa limitada comprensión de la inaplicabilidad, el efecto de la sentencia en el tiempo se restringe

${ }^{107}$ STC Rol No 1.881, 3 de noviembre de 2011, con relación al fallo de la Corte de Apelaciones de Santiago, 9 de diciembre de 2011, Rol № 6.787-2010. A la fecha en que se redactaron estas líneas esta última sentencia se encontraba apelada y radicada en la Sala constitucional de la Corte Suprema (Rol No 12.635-2011).

${ }^{108}$ Corte de Apelaciones de Santiago, 9 de diciembre de 2011, Rol No 6.787-2010, considerando $12^{\circ}$. 
inapropiadamente respecto de actos jurisdiccionales y administrativos de ejecución de la ley. En la primera situación se encuentra el criterio que deslizó la Corte de Apelaciones de Valparaíso en el caso Ominami, fallado por el Tribunal Constitucional en abril de $2009^{109}$ y por la corte porteña en junio del mismo año. En este caso, la Corte de Valparaíso estimó que no era posible revisar la legalidad de una sentencia que se había dictado por un Ministro de Fuero antes de la declaración de inaplicabilidad y, por lo tanto, aplicando el precepto posteriormente declarado inaplicable (en este caso el art. 2331 del Código Civil):

"Que no obsta a lo concluido la sentencia del Tribunal Constitucional de fecha dieciséis de abril de dos mil nueve, que se encuentra agregada desde fs. 254 a 272, por cuanto el juez señor Torres Allú, la desconocía al dictar su fallo el doce de diciembre de dos mil siete y esta Corte no la puede considerar para resolver el recurso de casación en la forma porque, como se anotó, se fundamenta en el hecho que el juez de la causa aplicó una norma que nadie le había mencionado, quedando allí limitada la competencia de este tribunal"110.

Entre los casos en que la supuesta no retroactividad de la declaración de inaplicabilidad impide la declaración de ilegalidad de actos administrativos de ejecución del precepto declarado inaplicable pueden anotarse algunos fallos Gaete González y Cortés Zamora de la saga Crédito Universitario y, particularmente, el fallo de la Tercera Sala de la Corte Suprema en el caso Gómez Montoya, sobre bonos por desempeño institucional en el Poder Judicial.

En Gaete González, no obstante el Tribunal Constitucional había acogido una acción de inaplicabilidad en contra del art. $1^{\circ}$ de la Ley No $19.989^{111}$, la Séptima Sala de la Corte de Santiago estimó que dicho fallo no afectaba la legalidad de un acto administrativo dictado con anterioridad a la sentencia de inaplicabilidad:

"Que el Excmo. Tribunal Constitucional declaró inaplicable el artículo $1^{\circ}$ de la Ley 19.989, pronunciamiento que tiene efecto inhibitorio respecto a esta Corte, en cuanto a que el citado precepto legal no puede ser considerado o aplicado por este Tribunal al resolver lo que en esta sede se ha propuesto.

Sin embargo, el recurso de protección de autos reprocha el actuar de la Tesorería General de la República que descontó de la devolución anual de impuestos a la renta del año 2008 del recurrente, a través del formulario 22 , la suma de $\$ 438.020$ por concepto de deuda de crédito universitario, acto que al momento en que se ejecutó lo

${ }^{109}$ STC Rol No $1.185,16$ de abril de 2009.

${ }^{110}$ Corte de Apelaciones de Valparaíso, 16 de junio de 2009, Rol No 800-08, considerando $5^{\circ}$.

${ }^{111}$ STC Rol No 1.438, 7 de septiembre de 2010. 
fue en cumplimiento de la obligación legal que al órgano administrativo le impuso la Ley $N^{\circ} 19.989$, de suerte que no cabe reprochar tal conducta hoy de ilegal"112.

En el mismo sentido, en Cortés Zamora, frente a un fallo estimatorio casi idéntico de inaplicabilidad ${ }^{113}$, la Sexta Sala de la misma Corte resolvió:

"Que, en primer lugar, se hace necesario consignar que la declaración de inaplicabilidad pronunciada por el Tribunal Constitucional, en sentencia de 7 de septiembre de 2010, cuya copia rola a fojas 42, no tiene influencia en la resolución de esta causa. En efecto, la Tesorería General de la República, recurrida en este proceso constitucional de naturaleza cautelar, aplicó el precepto legal cuestionado, artículo $1^{\circ}$ de la Ley No 19.989, antes de que fuera declarado inaplicable por la Magistratura Constitucional. Aún más, puede decirse que se encontraba obligada a proceder conforme se lo ordena ese mandato legal al haber recibido de la entidad acreedora la comunicación respectiva" 114 .

El camino que habían sugerido estas dos sentencias fue seguido después por la Corte Suprema en Gómez Montoya, en un razonamiento que dio lugar a diversos comentarios difundidos en la prensa legal escrita y electrónica nacional ${ }^{115}$. Como se sabe, en dicho caso el Tribunal Constitucional declaró inaplicable, por discriminatorio y lesivo a la propiedad, un precepto legal que excluía al requirente del acceso a un incentivo profesional ${ }^{116}$. Siguiendo la misma línea argumentativa de la Corte de Santiago, la Corte Suprema desconoció el fallo de inaplicabilidad y afirmó el carácter no retroactivo de la sentencia de inaplicabilidad:

"[L]a aplicación de la norma precedentemente transcrita fue hecha por la recurrida antes de la declaración de inaplicabilidad efectuada por el Tribunal Constitucional, de forma que se encontraba obligada a obrar como lo ordena ese mandato legal (...) Así las cosas, la actuación de la recurrida que se impugna se agotó con la aplicación que en su momento hizo del artículo $4^{\circ}$ de la Ley $\mathrm{N}^{\circ} 19.531$ (...) [P]or consiguiente el hecho de que con posterioridad el Tribunal Constitucional haya declarado inaplicable el precepto legal (...) no implica que tal proceder sea ilegal, por lo que para estimar que obró en disconformidad con la normativa existente a la fecha del pago

\footnotetext{
${ }^{112}$ Corte de Apelaciones de Santiago, 8 de octubre de 2010, Rol No 7.767-2009, considerando $3^{\circ}$, cursivas añadidas.

${ }^{113}$ STC Rol No 1.437, 7 de septiembre de 2010.

${ }^{114}$ Corte de Apelaciones de Santiago, 23 de junio de 2011, Rol No 7833-2009, considerando 6 ${ }^{\circ}$, cursivas añadidas.

115 Szczaranski, Clara (2011) y Covarrubias (2011).

116 STC Rol No 1.801, 12 de abril de 2011.
} 
cuestionado es necesario que tal proceder sea retroactivamente considerado contrario a la ley aplicable al caso concreto (...).

[D]esde esta perspectiva, el reproche de ilegalidad contenido en el artículo 20 de la Carta Fundamental debe existir al momento en que se verifica el actuar que inflige el daño al recurrente, pues de otra forma se agrega al obrar de la recurrida un factor de incerteza o falta de previsibilidad que no es admisible considerar por esta vía"117.

El criterio de la Corte Suprema no es nuevo. Además de estar presente en los citados Cortes Zamora y Gaete González de la Corte de Santiago, el discurso del precepto pretéritamente aplicado estuvo presente durante las últimas décadas el anterior modelo de inaplicabilidad, permitiendo a la Corte Suprema desestimar inaplicabilidades alegando que el precepto legal ya había sido aplicado y que la inaplicabilidad no era la vía idónea para revisar las consecuencias de situaciones jurídicas ya creadas y consolidadas ${ }^{118}$. Incluso se advierte alguna reminiscencia de ella después de la entrada en vigencia de la reforma de la Ley No 20.050, en el voto concurrente del Ministro Libedinsky a la STC Rol No 481 de 4 de julio de 2006 y en la disidencia al oficio de la Sala Civil de la Corte Suprema ${ }^{119}$ que planteó la cuestión de inaplicabilidad que dio origen a la STC Rol No 707 de 2007. Este último dato, posterior a la reforma del 2005, da buena noticia sobre el modo en que parte de la Corte Suprema seguiría replicando los antiguos estándares de la inaplicabilidad.

Sin perjuicio de que el argumento de la legalidad inatacable ratione tempore se remonta al modelo de inaplicabilidad que fue superado con la reforma del 2005, es preciso recordar que el nuevo diseño aporta razones adicionales para sostener que el criterio judicial del fallo Gómez Montoya (y sus precedentes) debe ser ajustado. En efecto, la irretroactividad de la sentencia se encuentra limitada a la competencia de inconstitucionalidad (art. 93.6 CPR), de modo que la única limitación temporal de la inaplicabilidad radica en que la gestión debe encontrarse pendiente. El hecho de encontrarse en segunda instancia, o sometida a la revisión que es propia de recursos que no constituyen instancia, no impide que la posterior desaparición

\footnotetext{
${ }_{117}$ Corte Suprema, 30 de noviembre de 2011, Rol No 4.518-2011, considerandos $3^{\circ}-5^{\circ}$.

${ }^{118}$ Véase Saenger y Bruna (2006), pp. 133 y ss. Véanse, entre otros, Corte Suprema, 13 de mayo de 1994, Fallos del Mes 426, pp. 236 y ss; y Corte Suprema, 13 de mayo de 1994, Gaceta Jurídica 167, pp. 42 y ss.

119 "Señala finalmente la Corte Suprema que este acuerdo se adoptó con el voto en contra del Presidente de la Sala, Ministro Jorge Rodríguez Ariztía, quien estimó que el presunto conflicto no versa sobre la inaplicabilidad actual de los artículos 15 y 16 impugnados, sino acerca de los efectos o consecuencias jurídicas derivadas de la aplicación pretérita de aquellas normas que se invocaron y aplicaron con anterioridad, sin reclamación oportuna. Por lo tanto, las normas citadas del Decreto Ley $\mathrm{N}^{\circ} 2.695$ ya fueron aplicadas y produjeron sus efectos, por lo que en el caso sub lite su aplicación resulta indirecta para la resolución del asunto controvertido", STC Rol No 707, 25 de octubre de 2007, parte preliminar.
} 
del precepto legal -propia de la declaración de inaplicabilidad permita calificar como ilegal un acto pretérito administrativo o jurisdiccional de ejecución de la ley declarada inaplicable. Como afirmó correctamente la Corte de Valparaíso en Bahamonde Jarufe, la declaración de inaplicabilidad conduce a la declaración de ilegalidad del acto fundado en el solo precepto declarado inaplicable. La afirmación contraria esteriliza la sentencia de inaplicabilidad y la deja en el ineficaz limbo de la vieja regla castellana: se acata pero no se cumple.

\section{CONCLUSiOnes}

1. La Ley de reforma constitucional No 20.050, tanto en su formulación textual como en el modo en que ha sido interpretada por el Tribunal Constitucional, supuso una alteración mayor del viejo proceso de inaplicabilidad. En sus actuales características, el diseño institucional de la inaplicabilidad incardina un nuevo órgano revisor del ejercicio de la función jurisdiccional: el Tribunal Constitucional. A partir de este diseño, más o menos improvisado y más o menos original, se colige como consecuencia la superposición y necesaria coordinación entre las competencias emanadas de los artículos 76 y 93.6 de la Constitución. Siendo esta última competencia una atribución de naturaleza jurisdiccional, que no puede por tanto ser calificada de función legislativa, el efecto de las decisiones propias del proceso de inaplicabilidad puede ser examinado con propiedad a partir de la noción de cosa juzgada, sin perjuicio de ajustar sus alcances a las peculiaridades de dicho proceso constitucional.

2. Una adecuada comprensión de los efectos intra-procesales de los fallos de inaplicabilidad exige separar las sentencias de fondo de las sentencias que no son de mérito. Entre estas últimas es posible identificar un efecto no equivalente al de la cosa juzgada. En efecto, las sentencias de inadmisión a trámite no obstan a la formación de un nuevo proceso de inaplicabilidad para la misma gestión, en tanto que las de inadmisibilidad en el estado actual de la jurisprudencia generan un efecto que se ha denominado de preclusión. Este último efecto se extiende a toda la gestión, dadas la identidad de las partes, de gestión, de pretensión y de fundamentos, elementos todos que deben ser comprendidos en el preciso contexto concreto del instituto de la inaplicabilidad.

3. La sentencia desestimatoria de la cuestión de inaplicabilidad genera, de acuerdo con la LOCTC un efecto impeditivo equivalente al de la cosa juzgada, que obsta a la incoación de un nuevo proceso de inaplicabilidad y devuelve al tribunal de la gestión la libertad para fallar la causa en su mérito fáctico y jurídico. No siendo el objeto de la inaplicabilidad la decisión del fondo, sino sólo la ordenación y eventual corrección de sus posibles motivaciones, el fallo estimatorio no garantiza 
éxito en la gestión pendiente, del mismo modo en que un fallo desestimatorio no pronostica el fracaso del proceso principal.

4. Las sentencias desestimatorias con interpretación suelen no estar exentas de dificultades de interpretación y son desaconsejadas por diversas razones que se han explicado en este trabajo. Con todo, ellas no dejan de ser vinculantes para el juez de la gestión. Esta obligatoriedad de las sentencias interpretativas es afirmada desde una perspectiva que, dadas las particularidades de la cuestión de inaplicabilidad, se aparta de aquella doctrina que sostiene que los fallos interpretativos de rechazo se acercan a los dominios de la casación.

5. Las mismas particularidades de la cuestión de inaplicabilidad, comprendida como herramienta de control concreto, obligan en otros casos a modular el efecto impeditivo de la cosa juzgada. En particular se ha examinado el caso de las sentencias desestimatorias fundamentadas en una apreciación o prognosis del Derecho que luego es desvirtuada por el curso real de la gestión.

6. La sentencia estimatoria de inaplicabilidad es obligatoria y retira el precepto legal de las posibilidades de motivación de la sentencia, generando aquello que el Tribunal ha identificado con la idea de "vacío legal". La inexistencia de un vínculo formal de control procesal o disciplinario entre el Tribunal Constitucional y el resto de los tribunales de la nación no resta valor a sus sentencias pero añade una exigencia de lealtad hacia el efecto útil de las competencias constitucionales ejercidas por un órgano constitucional. Esta lealtad se refuerza con la comprensión coordinada de las atribuciones contenidas en los artículos 93.6 y $76 \mathrm{CPR}$.

7. La sentencia estimatoria no libera a los jueces del principio de inexcusabilidad y del deber de llenar el presunto vacío con reglas o principios de carácter general, sea que el fallo termine por acoger o desestimar las pretensiones procesales de las partes.

8. La sentencia estimatoria puede devenir en inaplicable por razones que no afectan su integridad. Entre estas razones no se cuentan aquellos casos en que los tribunales se niegan a colmar la supuesta laguna dejando sin aplicación otros preceptos no afectados por la decisión de inaplicabilidad, ni las sentencias que se niegan revisar la legalidad de un acto de ejecución de la ley a partir de un supuesto carácter no retroactivo de la sentencia de inaplicabilidad. Decisiones de esta naturaleza conducen a la esterilidad del fallo de inaplicabilidad y al desvío de las competencias reconocidas en los arts. 76 y $93.6 \mathrm{CPR}$.

\section{BiBLIOGRAFÍA CITADA}

AldunATE, Eduardo (1993): "Jurisdicción constitucional y cosa juzgada constitucional”, en Revista Chilena de Derecho XX/ 2-3, T. I, pp. 355-359 
Aldunate, Eduardo (2007): "La reforma constitucional del año 2005 desde la teoría del Derecho y la teoría de la Constitución”, en Revista de Derecho Público 69, I, 35-44.

Biblioteca del Congreso Nacional (2009): Historia de la Ley $N^{\circ}$ 20.381. Modifica la Ley $N^{\circ}$ 17.997, Orgánica Constitucional del Tribunal Constitucional (s.l.).

Blasco Soto, María del Carmen (1994): "Reflexiones en torno a la fuerza de cosa juzgada en la sentencia dictada en la cuestión de inconstitucionalidad", en Revista Española de Derecho Constitucional 41, pp. 35-62;

BoCANEgra, Raúl (1981): "Sobre el alcance de las sentencias del Tribunal Constitucional”, en AA.VV., El Tribunal Constitucional (Madrid, Instituto de Estudios Fiscales) vol. I, pp. 509-536.

BoCANEgra, Raúl (1982): El valor de las sentencias del Tribunal Constitucional (Madrid, Instituto de Estudios de Administración Local).

Bordalí, Andrés (2009): "Jueces constitucionales. Un poder incómodo", en Nogueira, Humberto (Coord.), La ciencia del Derecho procesal constitucional. Estudios en homenaje a Héctor Fix-Zamudio en sus cincuenta años como investigador del derecho (Santiago de Chile, Librotecnia), pp. 47-71.

Celoto, Alfonso (2009): Questioni di giustizia costituzionale (Napoli, Editoriale Scientifica).

Couso, Javier (2010): "La nueva ley orgánica del Tribunal Constitucional: encuentros y desencuentros", en Anuario de Derecho público Universidad Diego Portales, pp. 38-54.

Couso, Javier y CodDou, Alberto (2010): “La naturaleza jurídica de la acción de inaplicabilidad en la jurisprudencia del Tribunal Constitucional: un desafío pendiente", en Estudios Constitucionales 8/2, pp. 389-430.

Covarrubias, Ignacio (2011): "La obligatoriedad de las sentencias del TC en entredicho", Mercurio Legal, 26 de diciembre de 2011, disponible en <http:// www.elmercurio.com/Legal/Noticias/Analisis-Juridico/2011/12/26/La-obligatoriedad-de-las-sentencias-del-TC-en-entredicho.aspx> [fecha de consulta: 28 de diciembre de 2011].

Filloy, Marylen y Soto, María de los Ángeles (2011): "Acción de inaplicabilidad por inconstitucionalidad: análisis jurisprudencial del período de marzo del año 2006 a marzo de 2010 en cuanto a los criterios de admisibilidad", Cuadernos del Tribunal Constitucional 44, pp. 177-293

Massmann, Nicolás (2009): "La admisibilidad del recurso de inaplicabilidad: a tres años de la reforma”, Ius et Praxis 15/1, pp. 263-293

MorTati, Costantino (1960): Istituzioni di Diritto Pubblico (Padova, Cedam) 
NAVARro, Enrique (2010): "Presupuestos de admisibilidad de la acción de inaplicabilidad”, Revista de Derecho Público 72, pp. 265-293

Nico, Anna Maria (2007): "Riflessioni in tema di applicabilità del giusto processo al guidizio di costituzionalità", en BALDUZZI, R. y Costanzo, P. (Eds.), Le zone d'mbra della giustizia costituzionale i giudizi sulle leggi, (Torino, Giappichelli), pp. 157-173.

Nogueira, Humberto (2006): "La sentencia constitucional en Chile: aspectos fundamentales sobre su fuerza vinculante", Estudios Constitucionales 4/1, pp. 97-124.

Nogueira, Humberto (2009): El Derecho procesal constitucional y la jurisdicción constitucional en Latinoamérica y sus evoluciones (Santiago de Chile, Librotecnia), 2009.

NúŃEZ, Manuel (2008): "El control de la igualdad en la aplicación de la ley como factor de expansión del controlo concreto de constitucionalidad de las leyes", en Fermandois, A. (Ed.), Sentencias destacadas 2007. Una mirada desde la perspectiva de las politicas públicas (Santiago de Chile, Ed. Libertad y Desarrollo), pp. 123-161.

PeÑA, Marisol (2008): "Inaplicabilidad por inconstitucionalidad: reciente jurisprudencia del Tribunal Constitucional chileno", Revista Iberoamericana de Derecho Procesal Constitucional 9, pp. 219-235.

PfefFer, Emilio (2011): "La inaplicabilidad, ¿̇un seudoamparo de derechos fundamentales?", en Asociación Chilena de Derecho Constitucional, Estudios sobre justicia constitucional. Libro homenaje a la Profesora Luz Bulnes Aldunate, (Santiago de Chile, Edit. Jurídica de Chile), pp. 203-224.

PICA, Rodrigo (2010): "La problemática de las partes y el contenido de la legitimación activa en la cuestión de inaplicabilidad por inconstitucionalidad de la ley", Revista de Derecho Universidad Católica del Norte (Coquimbo) 17/2, pp. 205-238.

PICA, Rodrigo (2010b): "El procedimiento correspondiente al proceso de inaplicabilidad en la Ley Orgánica del Tribunal Constitucional”, en Nogueira, Humberto (Coord.), Temas de Derecho Procesal Constitucional. Reflexiones jurídicas sobre competencias del Tribunal Constitucional y la nueva LOC del Tribunal Constitucional (Santiago de Chile, Librotecnia), pp. 237-261.

Pizzorusso, Alessandro (1981), "Las sentencias manipulativas del Tribunal Constitucional italiano", en AA.VV., El Tribunal Constitucional, Instituto de Estudios Fiscales, Madrid, vol. I, pp. 275-296.

Rodeville-Hermann, Jeannine (1989): "L'evolution des fonctions du principe d'autorité de chose jugée dans les rapports du juge administratif avec le juge 
judiciaire, le Conseil Constitutionnel et la Cour de Justice des Communautés Européennes", en Revue du Droit Public et de la Science Politique en France et a l'Etranger 6, pp. 1735-1779.

SAENGER, Fernando y BRUNA, Guillermo (2006): Inaplicabilidad por inconstitucionalidad. Jurisprudencia 1980-2005 (Santiago de Chile, Ed. Jurídica de Chile).

SzCZARANSKI, Clara (2011): “¿Desobediencia civil?”, Diario Constitucional, disponible en $<$ http://diarioconstitucional.cl/mostrararticulo.php?id=116> [fecha de consulta: 19 de enero de 2012]

VeGa, Francisco y ZÚNIIGA, Francisco (2006): "El nuevo recurso de inaplicabilidad por inconstitucionalidad ante el Tribunal Constitucional. Teoría y práctica”, Estudios Constitucionales 4/2, pp. 135-174.

Verdugo, Sergio (2010): "Inaplicabilidad y vicios de forma. ¿Un problema resuelto?, Revista de Derecho (Universidad Austral, Valdivia) XXIIII/2, pp. 83-112.

Vogel, Klaus (1988): "Rechtskraft und Gesetzkraft der Entscheindungen des Bundesverfassungsgerichts", en STARK, Christian (Dir.), Bundesverfassungsgerichts und die übrigen Verfassungsorgane. Festgabe aus Anlass des 25 jähringen Bestehens des Bundesverfassungsferichts (Frankfurt a.M., Peter Lang), pp. 568-627.

ZaGrebelsKy, Gustavo (1988): La giustizia costituzionale, (Bologna, Il Mulino), 1988.

ZAPATA, Patricio (2006): "Las sentencias atípicas en la jurisprudencia del Tribunal Constitucional chileno", Estudios Constitucionales 4/2 (2006), pp. 175-187.

ZAPATA, Patricio (2008): Justicia constitucional. Teoría y práctica en el Derecho chileno y comparado (Santiago de Chile, Ed. Jurídica).

ZúNiga, Francisco (2010): "La relación Tribunal Constitucional-Tribunales del fondo y los efectos de la sentencia de inaplicabilidad acerca de los presupuestos de la acción”, en Nogueira, Humberto (Coord.), Temas de Derecho Procesal Constitucional. Reflexiones jurídicas sobre competencias del Tribunal Constitucional y la nueva LOC del Tribunal Constitucional (Santiago de Chile, Librotecnia), pp. 263-353.

\section{JURISPRUDENCIA CITADA}

\section{a) Tribunal Constitucional de Chile}

STC Rol No 468, 9 de diciembre de 2006.

STC Rol No 472, 30 de agosto de 2006.

STC Rol No 473, 8 de mayo de 2007.

STC Rol No 478, 8 de agosto de 2006. 
STC Rol No 498, 2 de mayo de 2006.

STC Rol No 503, 19 de julio de 2006.

STC Rol No 522, 16 de agosto de 2006.

STC Rol No 529, 9 de noviembre de 2006.

STC Rol No 541, 21 de diciembre de 2006.

STC Rol No 551, 8 de agosto de 2006.

STC Rol No 558 (590), 5 de junio de 2007.

STC Rol No No 589, 21 de agosto de 2007.

STC Rol No 681, 26 de marzo de 2007.

STC Rol No 707, 25 de octubre de 2007.

STC Rol No 733, 21 de marzo de 2007.

STC Rol No 736, 29 de noviembre de 2007.

STC Rol No 739, 21 de agosto de 2007.

STC Rol No 739, 21 de agosto de 2007.

STC Rol No 739, 21 de agosto de 2007.

STC Rol No 747 (774), 31 de agosto de 2007.

STC Rol No 767, 30 de octubre de 2007.

STC Rol No 781, 27 de septiembre de 2007.

STC Rol No 790, 11 de diciembre de 2007.

STC Rol No 797, 11 de diciembre de 2007.

STC Rol No 806, 11 de diciembre de 2007.

STC Rol No 806, 11 de diciembre de 2007.

STC Rol No 808, 12 de agosto de 2010.

STC Rol No 810, 24 de enero de 2008.

STC Rol No 944, 13 de mayo de 2008.

STC Rol No 968, 9 de julio de 2008.

STC Rol No 979, 29 de noviembre de 2007.

STC Rol No 986, 30 de enero de 2008.

STC Rol No 993, 13 de mayo de 2008.

STC Rol No 996, 4 de diciembre de 2007.

STC Rol No 1.029, 24 de noviembre de 2008.

STC Rol No 1.133, 18 de noviembre de 2008.

STC Rol No 1.138, 8 de septiembre de 2008.

STC Rol No 1.140, 14 de enero de 2009.

STC Rol No 1.145, 21 de enero de 2010. 
STC Rol No 1.182, 18 de noviembre de 2008.

STC Rol No 1.185, 16 de abril de 2009.

STC Rol No 1.191, 19 de mayo de 2009.

STC Rol No 1.234, 7 de julio de 2009.

STC Rol No 1.282, 18 de diciembre de 2008.

STC Rol No 1.287, 8 de septiembre de 2009.

STC Rol No 1.288, 25 de agosto de 2009.

STC Rol No 1.288, de 25 de agosto de 2009.

STC Rol No 1.295, 6 de octubre de 2009.

STC Rol No 1.311, de 2 de abril de 2009.

STC Rol No 1.311, de 2 de abril de 2009.

STC Rol No 1.311, de 2 de abril de 2009.

STC Rol No 1.337, 20 de agosto de 2009.

STC Rol No 1.380, 3 de noviembre de 2009.

STC Rol No 1.405, 3 de agosto de 2010.

STC Rol No 1.406, 31 de diciembre de 2009.

STC Rol No 1.419, 0 de noviembre de 2010.

STC Rol No 1.437, 7 de septiembre de 2010.

STC Rol No 1.438, 7 de septiembre de 2010.

STC Rol No 1.445, 21 de enero de 2010.

STC Rol No 1.449, 9 de diciembre de 2010.

STC Rol No 1.463, 23 de septiembre de 2009.

STC Rol No 1.482, 21 de octubre de 2009.

STC Rol No 1.484, 5 de octubre de 2010.

STC Rol No 1.542, 31 de agosto de 2010.

STC Rol No 1.580, 27 de enero de 2011.

STC Rol No 1.584, 17 de junio de 2010.

STC Rol No 1.615, 20 de enero de 2011.

STC Rol No 1.671, 21 de abril de 2010.

STC Rol No 1.679, 15 de marzo de 2011.

STC Rol No 1.681, 11 de mayo de 2010.

STC Rol No 1.741, 15 de marzo de 2011.

STC Rol No 1.790, 4 de octubre de 2011.

STC Rol No 1.801, 12 de abril de 2011.

STC Rol No 1.852, 26 de julio de 2011. 
STC Rol No 1.881, 3 de noviembre de 2011.

STC Rol No 1.913, 9 de marzo de 2011.

STC Rol No 2.039, 20 de septiembre de 2011.

\section{b) Tribunales ordinarios de justicia}

1. Corte de Apelaciones de Concepción, 28 de diciembre de 2007, Rol No 3.208-2006, Arroyo c. Fisco de Chile.

2. Corte de Apelaciones de Santiago de 31 de julio de 2007, Rol No 29.4282004, Chilectra S.A. c. Zúñiga

3. Corte de Apelaciones de Santiago, 11 de diciembre de 2006, Rol No 7.2032006, Artigoitía c. Longueira.

4. Corte de Apelaciones de Santiago, 14 de noviembre de 2011, Rol No 101 2011, Reyes c. Aguas Andina.

5. Corte de Apelaciones de Santiago, 18 de octubre de 2011, Rol No 2.517-2008, Bordachar c. Pontifica Universidad Católica de Chile.

6. Corte de Apelaciones de Santiago, 23 de agosto de 2006, Rol No 2.257-2006, Soto y otro c. Girardi.

7. Corte de Apelaciones de Santiago, 23 de junio de 2011, Rol No 7.833-2009, Cortés c. Tesorería General de la República.

8. Corte de Apelaciones de Santiago, 24 de septiembre de 2008, Rol No 4.9722007, Peña c. Isapre ING.

9. Corte de Apelaciones de Santiago, 25 de abril de 2011, Rol No 8.063-2009, Espinoza c. Tesorería General de la República.

10. Corte de Apelaciones de Santiago, 8 de octubre de 2010, Rol No 7.767-2009, Gaete c. Tesorería General de la República.

11. Corte de Apelaciones de Santiago, 9 de diciembre de 2011, Rol No 6.7872010, Peralta y otros c. Soto, Oficial del Registro Civil de Santiago.

12. Corte de Apelaciones de Temuco, 17 de octubre de 2007, Rol No 1.048-2007, Morrison Cristi.

13. Corte de Apelaciones de Valparaíso, 16 de diciembre de 2008, Rol No 762008, Del Villar c. Universidad de Valparaiso.

14. Corte de Apelaciones de Valparaíso, 16 de junio de 2009, Rol № 800-2008, Ominami c. Comunicaciones Urbano S.A. y otro.

15. Corte de Apelaciones de Valparaíso, 8 de septiembre de 2008, Rol No 2962007, Balmaceda c. Pontificia Universidad Católica de Valparaiso y otro.

16. Corte Suprema, 13 de mayo de 1994, Fallos del Mes 426, pp. 236 y ss. Zamorano y otros c. Fisco. 
17. Corte Suprema, 13 de mayo de 1994, Gaceta Jurídica 167, pp. 42 y ss., Galleguillos c. Álvarez.

18. Corte Suprema, 26 de octubre de 2009, Rol No 7.779-2008. Fernández c. Isapre Colmena Golden Cross.

19. Corte Suprema, 30 de junio de 2011, Rol No 7.914-2008, Molina c. Fuenzalida y otros.

20. Corte Suprema, 30 de noviembre de 2011, Rol No 4.518-2011, Gómez c. Corporación Administrativa del Poder Judicial.

21. Cuarto Juzgado de Garantía de Santiago, RIT No 6.118-2009, RUC No 0900447112-9, Sánchez Eyquem.

22. Juzgado de Letras del Trabajo de Concepción, 13 de diciembre de 2011, RIT I-36-2010, Amigo c. Inspección Comunal del Trabajo.

23. Tribunal de Juicio Oral en lo Penal de Temuco, 29 de agosto de 2007, RIT No 73-2007, RUC 0700006159-4, Morrison Cristi.

24. Tribunal de Juicio Oral en lo Penal de Temuco, 9 de julio de 2008, RIT No 73-2007, RUC 0700006159-4, Morrison Cristi.

25. Tribunal de Juicio Oral en lo penal de Valparaíso, 23 de diciembre de 2010, RUC No 0700364853-7 y RIT No 186-2008, Arancibia Tognia.

26. Vigésimonoveno Juzgado Civil de Santiago, 21 de marzo de 2011, rol No C-28538-2009, Maira c. Fisco.

$$
\text { c) Otros }
$$

Corte de Casación italiana, sentencia No 23.016/2004, 17 de mayo de 2004. 